\title{
Direct photolysis of carbonyl compounds dissolved in cloud and fog droplets
}

\author{
S. A. Epstein, E. Tapavicza, F. Furche, and S. A. Nizkorodov \\ Department of Chemistry, University of California, Irvine, 1102 Natural Sciences 2, Irvine, CA 92697-2025, USA
}

Correspondence to: S. A. Epstein (scott.a.epstein@gmail.com)

Received: 13 April 2013 - Published in Atmos. Chem. Phys. Discuss.: 24 April 2013

Revised: 31 July 2013 - Accepted: 13 August 2013 - Published: 26 September 2013

\begin{abstract}
Gas-phase photolysis is an important tropospheric sink for many carbonyl compounds; however the significance of direct photolysis of these compounds dissolved in cloud and fog droplets is uncertain. We develop a theoretical approach to assess the importance of aqueous photolysis for a series of carbonyls that possess carboxyl and hydroxyl functional groups by comparison with rates of other atmospheric processes. We use computationally and experimentally derived effective Henry's law constants, hydration equilibrium parameters, aqueous hydroxyl radical $(\mathrm{OH})$ rate constants, and optical extinction coefficients to identify types of compounds that will (or will not) have competitive aqueous photolysis rates. We also present molecular dynamics simulations designed to estimate gas- and aqueous-phase extinction coefficients of unstudied atmospherically relevant compounds found in d-limonene and isoprene secondary organic aerosol. In addition, experiments designed to measure the photolysis rate of glyceraldehyde, an atmospherically relevant water-soluble organic compound, reveal that aqueous quantum yields are highly molecule-specific and cannot be extrapolated from measurements of structurally similar compounds. We find that only two out of the 92 carbonyl compounds investigated, pyruvic acid and acetoacetic acid, may have aqueous photolysis rates that exceed the rate of oxidation by dissolved $\mathrm{OH}$. For almost all carbonyl compounds lacking $\alpha, \beta$-conjugation that were investigated, atmospheric removal by direct photolysis in cloud and fog droplets can be neglected under typical atmospheric conditions.
\end{abstract}

\section{Introduction}

Oxidation of volatile organic precursors in the atmosphere produces highly functionalized water-soluble compounds (Saxena and Hildemann, 1996). These oxidation products typically contain several types of functional groups including carboxyls, carbonyls, hydroxyls, and peroxides. Lowvolatility products may partition into the particle phase, while high-volatility compounds will remain in the gas phase. In the presence of clouds and fog, water-soluble gasand particle-phase compounds can partition into the aqueous phase (Facchini et al., 1999; Ervens et al., 2011). Compounds dissolved in atmospheric water droplets may react with dissolved oxidants or undergo direct photolysis by actinic radiation. Aqueous oxidation processes have garnered much attention among atmospheric researchers (Seinfeld and Pandis, 1998; Finlayson-Pitts and Pitts, 2000; Vione et al., 2006), but the implications of direct aqueous photolysis remain uncertain.

It is well established that carbonyls weakly absorb radiation at wavelengths around $280 \mathrm{~nm}$ due to a forbidden $\pi^{*} \leftarrow n$ transition. Photodissociation of carbonyls in the gas phase is well studied, with the absorption cross sections and quantum yields published for a variety of compounds (Sander et al., 2011). However, aqueous photolysis quantum yields at actinic wavelengths of carbonyls dissolved in cloud and fog droplets are not well established. The photochemical behavior of carbonyl compounds dissolved in cloud and fog droplets is challenging to understand because carbonyls may oligomerize in the aqueous phase (Lim et al., 2010; Tan et al., 2012; Renard et al., 2013) and partially hydrate upon dissolution in water, leading to conversion to the nonphotoactive gem-diol form. In addition, the photolysis reac- 
tion mechanism in the gas and aqueous phase may be drastically different (Guzmán et al., 2006). In light of the limited data, we strive to determine which atmospherically relevant carbonyls may have competitive photolytic removal rates in cloud and fog droplets. In our previous publication (Epstein and Nizkorodov, 2012), we determined that compounds with large effective Henry's law constants $\left(>10^{4} \mathrm{M} \mathrm{atm}^{-1}\right)$ that do not suffer from significant suppression of photolysis by the solvent may have aqueous photolysis rates that are competitive with gas-phase photolysis. In this manuscript, we apply this analysis to a set of atmospherically relevant carbonyl compounds with the additional constraint that aqueous photolysis rates must be competitive with aqueous oxidation by hydroxyl radical $(\mathrm{OH})$ for direct aqueous photolysis to be a significant carbonyl sink.

Aqueous photolysis lifetimes depend on the optical extinction coefficients, actinic flux, and the photolysis quantum yields. In general, rate constants governing the aqueous photolysis of carbonyls will be lower than gas-phase photolysis rate constants for several reasons: absorption cross sections of carbonyl compounds can undergo a blue shift of approximately $10 \mathrm{~nm}$ upon dissolution in water (Xu et al., 1993), the shape of the absorption spectrum may change, aqueous quantum yields may be suppressed due to the excited state relaxation by the solvent molecules and the cage effect (Calvert and Pitts, 1966), and the fraction of the carbonyl in the photolabile (non-hydrated) form may be low. Even though the actinic flux may be enhanced slightly inside a water droplet relative to the interstitial air, the enhancement factor is thought to be relatively small, less than a factor of two (Nissenson et al., 2006; Mayer and Madronich, 2004), and therefore easily outweighed by the above effects. Carbonyl compounds may exhibit an increase in their maximum absorption upon dissolution in water (Bayliss and McRae, 1954), but the blue shift commonly seen in these compounds tend to negate this enhancement. The rate of oxidation by $\mathrm{OH}$ is typically enhanced in the aqueous phase due to high $\mathrm{OH}$ concentrations formed from cloud-specific processes such as the Fenton reaction (Vione et al., 2006). Photosynthesized production of $\mathrm{OH}$ from dissolved organics is another possible source of aqueous $\mathrm{OH}$, but it appears to be a minor contributor in cloud droplets (Albinet et al., 2010a). Oxidation of dissolved compounds by $\mathrm{OH}$ is typically the most significant oxidation sink, and as a first approximation, reaction with other radicals or radical anions may be neglected (Ervens et al., 2003a). For specific molecules examined in previous studies, the rates of aqueous oxidation by $\mathrm{OH}$ and aqueous photolysis can be comparable (Albinet et al., 2010b). Comparison of lifetimes due to aqueous-phase direct photolysis and aqueous-phase $\mathrm{OH}$ oxidation for a broader range of molecules will reveal the significance of aqueous photolysis in transforming carbonyl compounds in the atmosphere.

We develop a framework that allows for the prediction of the aqueous photolysis lifetime as a function of wavelength and maximal optical extinction associated with the

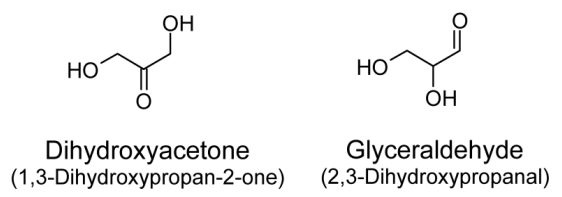

Fig. 1. Chemical structures of dihydroxyacetone and glyceraldehyde.

$\pi^{*} \leftarrow n$ transition in carbonyls. Measurements of aqueous quantum yields of atmospherically relevant compounds at actinic wavelengths are rare. In order to understand the range of possible aqueous quantum yields for atmospherically relevant carbonyls, we chose dihydroxyacetone and glyceraldehyde as surrogates for oxidized water-soluble atmospheric organic compounds.

Dihydroxyacetone and glyceraldehyde contain both carbonyl and hydroxyl functional groups (see Fig. 1), have large predicted effective Henry's law constants $\left(5.5 \times 10^{8} \mathrm{M} \mathrm{atm}^{-1}\right.$ (EPA, 2013) and $2 \times 10^{8} \mathrm{M} \mathrm{atm}^{-1}$ (Saxena and Hildemann, 1996), respectively), and do not hydrate completely in the aqueous phase (fraction unhydrated $\approx 77 \%$ (Glushonok et al., 2003) and 5\% (Glushonok et al., 1986) at $25^{\circ} \mathrm{C}$, respectively). In addition, glyceraldehyde has been identified as a product of isoprene oxidation (Fang et al., 2012) and may be present in automobile exhaust (Renzetti and Doyle, 1959). We use published measurements from Encinas et al. (1985) of dihydroxyacetone and compared them to the results of semi-quantitative experiments designed to constrain the quantum yield of its structural isomer, glyceraldehyde. These experiments, along with our modeling framework, allow us to identify carbonyl compounds where atmospheric removal by direct photolysis in cloud and fog droplets can be neglected relative to aqueous reactions with $\mathrm{OH}$.

We also aim to extend this framework to investigate carbonyl compounds contained in isoprene and d-limonene secondary organic aerosol (SOA). Experimental extinction coefficient measurements of simple carbonyl and dicarbonyl compounds are present throughout the literature. However, extinction measurements of multifunctional carbonyl compounds found in SOA and cloud droplets are less common due to the difficulty in isolating or synthesizing these complex molecules. In addition, these complex structures do not allow for estimations of spectroscopic properties from similar compounds. We apply density functional theory (DFT) molecular dynamics simulations to selected isoprene (Fang et al., 2012) and d-limonene (Jaoui et al., 2006) SOA products in order to predict their photophysical properties and identify compounds that may have competitive aqueous photolysis rates in the absence of experimental measurements. For predictions of electronic absorption spectra, one must accurately model vibrational effects of the molecules of interest. For rigid molecules, accurate vibronic spectra can be ob- 
tained using the Franck-Condon Herzberg-Teller approach with the harmonic oscillator approximation (Berger et al., 1998; Dierksen and Grimme, 2004). Alternatively, electronic spectra can be sampled over nuclear configurations using molecular dynamics (MD) with classical nuclei within the NVT ensemble (constant number of particles, volume, and temperature) (Röhrig et al., 2003; Sulpizi et al., 2003; Frelek et al., 2007; Tapavicza et al., 2011, 2013). The latter method, which we adopt here, produces band envelopes rather than individual vibronic transitions, but is comparatively inexpensive and straightforward for conformationally flexible systems.

\section{Materials and methods}

\subsection{Aqueous quantum yield measurements of glyceraldehyde}

Aqueous photolysis rate measurements were performed by photolyzing $0.1 \mathrm{M}$ solutions of D-glyceraldehyde (Sigma Aldrich, $98 \%$ purity) in nano-pure water. Radiation from a $150 \mathrm{~W}$ xenon arc lamp exited from an ellipsoidal reflector housing (PhotoMax, Newport model 60100), and passed through an interference filter centered at $300 \mathrm{~nm}$ with a $40 \mathrm{~nm}$ bandwidth (Edmund Optics NT67-817) to filter out higher-energy UV radiation outside of the actinic wavelength range. The resulting UV radiation was transferred to the photolysis cuvette using a liquid light guide (Edmund Optics Model NT53-691). The solution in the cuvette was irradiated from the top, with the extent of photolysis being monitored in real time with a UV-Vis spectrometer (Shimadzu, UV-2450) (Epstein et al., 2012). The photolysis of a solution containing $1.2 \mu \mathrm{M}$ azoxybenzene (Fisher Scientific, $98 \%$ ) and $146 \mu \mathrm{M}$ potassium hydroxide (Fisher Scientific) in ethanol (Rossville Goldshield) carried out immediately before and after glyceraldehyde photolysis according to the method described in Bunce et al. (1984) served as a chemical actinometer to quantify the lamp intensity. Actinometer measurements revealed that lamp intensities varied by less than $10 \%$ during a given experiment. The wavelength dependence of the spectral irradiance was determined with a separate UV-Vis spectrometer (Ocean Optics, USB4000). Both the glyceraldehyde solution and the actinometer solution were continuously mixed during photolysis with a cuvette stirring system (2 Mag-USA). Solutions were kept at $25^{\circ} \mathrm{C}$ with a temperature-controlled heating/cooling water jacket (Shimadzu Constant-Temperature Cell Holder). Semiquantitative measurements of glyceraldehyde concentration (initially $0.1 \mathrm{M}$ ) as a function of photolysis time were determined with an electrospray ionization mass spectrometer (ESI-MS) (Micromass model LCT, resolving power 6000) after derivatization with Girard's reagent $\mathrm{T}$ (Acros Organics, 99\%). Refer to the supplementary material (SM) Sect. 5 for details of the reaction between Girard's reagent $\mathrm{T}$ and carbonyls. A solution containing $0.9 \mathrm{mM}$ Girard's reagent T (GT) and $0.05 \mathrm{mM}$ tetraethylammonium chloride (Sigma Aldrich, $98 \%$ ) was used to dilute $100 \mu \mathrm{L}$ aliquots of the reacting glyceraldehyde mixture to $25 \mathrm{~mL}$ at several reaction times. Tetraethylammonium ion is an ideal internal standard as its ESI ionization efficiency and molecular weight are similar to those of the glyceraldehyde-GT adduct. The relative concentration of the glyceraldehyde-GT reaction product normalized by the internal standard concentration was tracked as a function of photolysis time.

\subsection{Comparison between aqueous- and gas-phase photolysis rates}

The maximum rate of aqueous photolysis relative to the rate of gaseous photolysis for a specific carbonyl compound in an air mass containing liquid water is governed by two main properties: the compound's affinity for the aqueous phase, captured with the effective Henry's law constant, and the fraction of the compound that remains in the photolabile unhydrated form upon dissolution, captured with the hydration equilibrium constant (Epstein and Nizkorodov, 2012). We define a cloudy air mass with a fractional liquid water content of $\mathrm{LWC}_{\mathrm{v}}$ (volume of liquid water per volume of air) containing a compound with an effective Henry's law constant of $K_{H}$, and a temperature of $T$ at equilibrium. We define the parameter $Z$ as the ratio of the rate of photolysis of a specific species in the gas phase and the aqueous phase:

$Z=\frac{\frac{\mathrm{d} n_{h v}^{\text {gas }}}{\mathrm{d} t}}{\frac{\mathrm{d} n_{h v}^{\text {aq }}}{\mathrm{d} t}}=\frac{J_{\mathrm{gas}} \cdot C_{\mathrm{gas}}}{J_{\mathrm{aq}} \cdot C_{\mathrm{aq}}^{\text {free }}}$,

where $J_{\text {gas }}$ and $J_{\text {aq }}$ are the gas- and aqueous-phase photolysis rate constants, respectively; $C_{\text {gas }}$ is the gas-phase concentration of the species of interest; and $C_{\mathrm{aq}}^{\text {free }}$ is the aqueous-phase concentration of the photolabile-free form of the carbonyl of interest. The ratio between the gas- and total aqueous-phase concentrations $\left(C_{\mathrm{gas}} / C_{\mathrm{aq}}^{\mathrm{total}}\right)$ is

$$
\frac{C_{\mathrm{gas}}}{C_{\mathrm{aq}}^{\text {total }}}=\left(R \cdot T \cdot \mathrm{LWC}_{\mathrm{v}} \cdot K_{H}\right)^{-1},
$$

where $R$ is the ideal gas constant. The fraction of total mass residing in the aqueous phase (FAQ) is therefore

$$
\mathrm{FAQ}=\frac{C_{\mathrm{aq}}^{\text {total }}}{C_{\mathrm{aq}}^{\text {total }}+C_{\mathrm{gas}}}=\left[\left(R \cdot T \cdot \mathrm{LWC}_{\mathrm{v}} \cdot K_{H}\right)^{-1}+1\right]^{-1} \text {. }
$$

The ratio of the total aqueous and aqueous-free-carbonyl (i.e., unhydrated) concentration is related to the hydration constant. For a mono-carbonyl,

$$
\frac{C_{\mathrm{aq}}^{\text {total }}}{C_{\mathrm{aq}}^{\text {free }}}=1+K_{\text {hyd }},
$$


where $K_{\text {hyd }}$ is the hydration constant. We use a more complicated functional form to model di-carbonyls that takes hydration of the second carbonyl group into consideration (see the SM Sect. 1). The fraction of the aqueous carbonyl that is free in solution $\left(\alpha_{\mathrm{uh}}\right)$ is therefore

$\alpha_{\text {uh }}=\left(1+K_{\text {hyd }}\right)^{-1}$.

Substituting Eqs. (2) and (4) into Eq. (1) yields

$Z=\frac{\frac{\mathrm{d} n_{h v}^{\text {gas }}}{\mathrm{d} t}}{\frac{\mathrm{d} n_{h v}^{\mathrm{aq}}}{\mathrm{d} t}}=\frac{J_{\mathrm{gas}}}{J_{\mathrm{aq}}} \frac{K_{\mathrm{hyd}}+1}{\left(R \cdot T \cdot \mathrm{LWC}_{\mathrm{v}} \cdot K_{H}\right)}$.

Since aqueous-phase rate constants are generally suppressed from the corresponding gas-phase value, $J_{\mathrm{aq}} \leq J_{\mathrm{gas}}$, and

$Z=\frac{\frac{\mathrm{d} n_{h v}^{\text {gas }}}{\mathrm{d} t}}{\frac{\mathrm{d} n_{h v}^{\mathrm{aq}}}{\mathrm{d} t}} \geq \frac{K_{\mathrm{hyd}}+1}{\left(R \cdot T \cdot \mathrm{LWC}_{\mathrm{v}} \cdot K_{H}\right)}$.

For a mono-carbonyl, the value of $Z$ is a function of the hydration equilibrium constant, temperature, the liquid water content of the air mass, and the effective Henry's law constant. While effective Henry's law constants (Sander, 1999) and hydration equilibrium constants (Bell and Gold, 1966) were measured for a significant number of simple carbonyls, few measurements exist for more complicated multifunctional molecules. Consistent with previous researchers, we assume that the kinetics of hydration is considerably faster than aqueous photolysis and aqueous oxidation by $\mathrm{OH}$ (Doussin and Monod, 2013; Ervens and Volkamer, 2010), and therefore can be treated with the equilibrium approach described above.

For effective Henry's law predictions of compounds without published experimental measurements, we employed HENRYWIN v 3.20 (EPA, 2011), developed by the United States Environmental Protection Agency (EPA) and based on methodology described in Hine and Mookerjee (1975) and Meylan and Howard (1991). Several other models designed to predict Henry's law constants exist in the literature; Dearden and Schüürmann (2003) and Raventos-Duran et al. (2010) provide thorough comparisons of these methods. Experimental measurements were used where possible (Buttery et al., 1971; Sander et al., 2011; Zhou and Mopper, 1990; Staudinger and Roberts, 1996; Betterton and Hoffmann, 1988; Pocker et al., 1969; Ip et al., 2009). We used either group or bond contribution estimates for effective Henry's law predictions. For a specific type of chemical functionality, we employed the method that most accurately reproduced effective Henry's law measurements of compounds containing the same functionality (typically the lower molecular weight compounds within the specific functional group). Prediction with group contribution methods may not be possible for small compounds containing multiple functional groups as the specific arrangement of molecules was not captured by the training data set. In these cases, bond estimation methods were employed. We expect some of the scatter in $K_{H}$ vs. carbon number to be a result of variations in estimation methods.

For predictions of hydration equilibrium constants from molecular structure, we used SPARC v4.6 (Karickoff et al., 2011) based upon work done by Hilal et al. (2005). Experimental measurements of $K_{\text {hyd }}$ were used where possible (Winkelman et al., 2002; Sham and Joens, 1995; Buschmann et al., 1980; Guthrie, 1978; Doussin and Monod, 2013; Bell and Gold, 1966; Tur'yan, 1998; Amyes and Richard, 2007; Esposito et al., 1999). We were unable to use pH-dependent hydration constants due to a lack of sufficient experimental data and prediction capabilities. Most of the experimental hydration constants used to construct the SPARC v4.6 model were reported under basic conditions (Hilal et al., 2005).

\subsection{Comparison between aqueous photolysis and aqueous oxidation by $\mathrm{OH}$ rates}

After identifying compounds that may have significant aqueous photolysis rates relative to their corresponding gas-phase photolysis rates, we investigated if aqueous photolysis rates can compete with the rate of oxidation by dissolved OH. $Q$ is defined as the ratio of the rate of oxidation by $\mathrm{OH}$ and the rate of direct photolysis in the aqueous phase:

$Q=\frac{\frac{\mathrm{d} n_{\mathrm{OH}}^{\mathrm{aq}}}{\mathrm{d} t}}{\frac{\mathrm{d} n_{h v}^{\mathrm{aq}}}{\mathrm{d} t}}=\frac{k_{\mathrm{OH}}[\mathrm{OH}]}{J}$,

where $k_{\mathrm{OH}}$ is the second-order rate constant for reaction with $\mathrm{OH}$ in the aqueous phase, $[\mathrm{OH}]$ is the aqueous concentration of $\mathrm{OH}$, and $J$ is the aqueous photolysis rate constant. Experimentally determined aqueous $\mathrm{OH}$ rate constants were used when available (Buxton et al., 1988, 1997; Monod et al., 2005; Jürgens et al., 2007; Schaefer et al., 2012; Ervens et al., 2003b), but measurements of many mono- and di-carbonyls are not present in the literature. Therefore, we used structure activity relationships (SARs) from Monod and Doussin (2008) and from Doussin and Monod (2013) to estimate aqueous $\mathrm{OH}$ rate constants for a variety of carbonyls. These relationships accurately predict rate constants for $76 \%$ of 102 distinct compounds within $\pm 40 \%$ of their experimental values (Doussin and Monod, 2013). This method, based on the gas-phase $\mathrm{OH}$ rate constant structure activity model originally proposed by Atkinson (Atkinson, 1987; Kwok and Atkinson, 1995), provides an estimate of $\mathrm{OH}$ reactivity based on the reactivity of all hydrogen atoms and the influence of nearby groups. These aqueous SARs, first developed in Monod and Doussin (2008) and refined to include carbonyls in Doussin and Monod (2013), incorporate the effects of adjacent ( $\alpha$-position) and $\beta$-position groups. We were unable to make rate constant predictions of unsaturated compounds because they were absent in the training data set.

Hydration and acid-base equilibria were accounted for in the rate constant predictions. Rate constants were calculated 
for gem-diol and free carbonyl forms and then weighted by the fraction of each present at equilibrium as explained in Doussin and Monod (2013). Predictions of $k_{\mathrm{OH}}$ for each dicarbonyl involved SAR calculations of four distinct species: the free carbonyl, two partially hydrated species, and the fully hydrated form of the molecule. For acids that ionize in solution, we calculated $k_{\mathrm{OH}}$ for both the free acid and anion form and then weighted the rate based on the relative fraction of each present at a droplet $\mathrm{pH}$ of 2 . Cloud and fog droplet $\mathrm{pH}$ typically ranges from 2 to 6 (Finlayson-Pitts and Pitts, 2000). At the lower $\mathrm{pH}$ limit, the acid/anion equilibrium for most carboxylic acids is shifted towards the free acid. Since free acids are generally less reactive towards $\mathrm{OH}$ than their corresponding anions, the overall consumption rate calculated at $\mathrm{pH}=2$ represents the lower limit (i.e., $\mathrm{OH}$ reactivity with the acid and its anion will increase at larger $\mathrm{pH}$ values). As we will show below, reaction with $\mathrm{OH}$ is faster than photolysis for most compounds investigated in this work, so using the lower limit for the $\mathrm{OH}$ reactivity calculated at $\mathrm{pH}=2$ will not affect our conclusions. Acid dissociation constants $\left(p K_{\mathrm{A}}\right)$ were obtained from measurements (Dawson et al., 1989; Brown et al., 1955; IUPAC et al., 1979) when available or predicted from theory using SPARC v4.6 (Karickoff et al., 2011).

In both the aqueous and gaseous phase, the photolysis rate constant is a function of the absorption cross section, $\sigma$; the photolysis quantum yield, $\Phi$; and the spectral flux density, $F_{\mathrm{A}}$ :

$J=\int F_{\mathrm{A}}(\lambda) \cdot \Phi(\lambda) \cdot \sigma(\lambda) \cdot d \lambda$

For liquids, absorption cross sections are typically written as extinction coefficients in units of $\mathrm{M}^{-1} \mathrm{~cm}^{-1}$ and are based on $\log _{10}$ (decadal) absorbance measurements. To simplify the calculations, we assume that the extinction coefficients describing the carbonyl $\pi^{*} \leftarrow n$ transition follow a Gaussian dependence on wavelength, which is reflected in previous aqueous extinction coefficient measurements of similar compounds (Malik and Joens, 2000; Bacher et al., 2001):

$\varepsilon(\lambda) \approx \varepsilon_{\max } \cdot \exp \left[\frac{-4 \cdot \ln (2) \cdot\left(\lambda-\lambda_{\max }\right)^{2}}{w^{2}}\right]$,

where $\varepsilon_{\max }$ is the maximum extinction coefficient at a wavelength of $\lambda_{\max }$ (the wavelength of maximum absorption) and $w$ is the full width at half maximum (FWHM). The full width $w$ was obtained from fitting measured extinction coefficients from a data set representing several ketones and aldehydes, along with dihydroxyacetone and glyceraldehyde. We find that $w=42 \mathrm{~nm}$ best describes several published extinction coefficients from Xu et al. (1993) and this work. As an approximation, we write the photolysis quantum yield as an average value over all relevant wavelengths:

$J=\frac{\langle\Phi\rangle}{N_{\mathrm{AV}}} \varepsilon_{\max } \cdot \ln (10) \int \mathrm{F}_{\mathrm{A}}(\lambda) \cdot \exp \left[\frac{-4 \cdot \ln (2) \cdot\left(\lambda-\lambda_{\max }\right)^{2}}{w^{2}}\right] d \lambda$, where $N_{\mathrm{AV}}$ is Avogadro's number. We can then define the lifetime due to photolysis, $\tau_{h v}$, as

$\tau_{h v}=J^{-1}$.

Correspondingly, the lifetime due to oxidation by $\mathrm{OH}, \tau_{\mathrm{OH}}$, is

$\tau_{\mathrm{OH}}=\left(k_{\mathrm{OH}}[\mathrm{OH}]\right)^{-1}$.

Comparison of these lifetimes using the branching ratio, $Q=$ $\tau_{h v} / \tau_{\mathrm{OH}}$, will indicate compounds that have aqueous photolysis rates that are competitive with aqueous oxidation by $\mathrm{OH}$.

Di-carbonyl compounds with adjacent carbonyl groups (1,2-dicarbonyls) have an additional $\pi^{*} \leftarrow n$ absorption peak arising from strong exciton splitting, which is present in the visible wavelength range (e.g., gas-phase glyoxal has a wellknown absorption band around $400 \mathrm{~nm}$ ). Quantum yields from the lower-energy visible light are likely smaller than corresponding UV quantum yields, but the actinic flux is larger in the visible range. We are unable to accurately model the photolysis rate contribution of this band due to the uncertain dependence of wavelength on photolysis yield.

In order to provide a more comprehensive analysis, we also determined rates of gas-phase oxidation by $\mathrm{OH}$ for all the compounds included in this work. Experimental rate constants were used when available (Atkinson et al., 2000, 2006; Albaladejo et al., 2002; Bowman et al., 2003; Garcia-Jiminez et al., 2005; Wallington and Kurylo, 1987; Rogers, 1989; Dagaut et al., 1988; Zhou et al., 2008). We used SARs from Atkinson (1987) and Kwok and Atkinson (1995) to estimate rates of compounds without published measurements.

\subsection{Computational chemistry methods for predictions of d-limonene and isoprene SOA spectroscopic properties}

We performed electronic structure calculations to estimate extinction coefficients for several atmospherically relevant compounds. To evaluate the accuracy of this method, we compared the calculated extinction coefficients of several compounds with their published values. We then calculated the extinction coefficients of four compounds identified in dlimonene and isoprene SOA, for which no absorption spectra are currently available. All electronic structure calculations were carried out using the TURBOMOLE version 6.3 quantum chemistry package (http://www.turbomole.com) and employed the split-valence plus polarization (SVP) basis set (Schafer et al., 1992). Ground state energies and nuclear gradients used in geometry optimizations and MD simulations were computed using the Gaussian basis set implementation of density functional theory (Treutler and Ahlrichs, 1995). Default convergence criteria were used. Geometry optimizations and electronic spectra calculations were done using the hybrid exchange correlation functional of Perdew, Burke, and Ernzerhof (PBE0) (Perdew et al., 1996a). For 
MD simulations, the generalized gradient approximation PBE functional of Perdew, Burke, and Ernzerhof (Perdew et al., 1996b) was used in combination with the resolution of identity (RI) approximation (Weigend and Häser, 1997). Electronic excitation energies and oscillator strengths were computed with the implementation of time-dependent density functional theory (TDDFT) of TURBOMOLE (Furche and Rappoport, 2005). A total of four excited states were computed in addition to the ground state. To simulate solvent effects of water, we employed the conductor-like polarizable continuum method (COSMO) (Klamt and Schurmann, 1993) in the spectra calculations using a dielectric constant of 80.1 (Haynes, 2012).

Computed excitation energies and oscillator strengths were used to simulate an absorption spectrum with a normalized Gaussian line shape, $\rho(\lambda)$, for each excitation. We applied a broadening with a FWHM between 0.1 and $1.5 \mathrm{eV}$ for each band to promote the best agreement with experimental spectra. The absorption spectrum for a given excitation was then computed using

$\varepsilon(\lambda)=2.303 \frac{4 \pi^{2} q_{e}^{2}}{3 \hbar c} N_{A V} \rho(\lambda) f$,

where $\hbar$ is the reduced Planck constant, $f$ is the oscillator strength, $q_{\mathrm{e}}$ is the electronic charge, and $\mathrm{c}$ is the velocity of light. First, we applied this procedure to compute absorption spectra for the excitation energies and oscillator strengths obtained by single point (SP) calculations of the ground state equilibrium geometries. Second, to include vibronic effects in the spectrum, we also generated an ensemble of geometries by ground state ab initio Born-Oppenheimer MD. The absorption spectrum was then computed in the same way for each of the 200 randomly selected geometries. The vibronic spectrum was obtained as an average over these 200 spectra. For all MD simulations, to obtain smooth absorption spectra, the computed oscillator strengths were broadened using a Gaussian lineshape function with FWHM of $0.1 \mathrm{eV}$. This value resulted in the best overall agreement with the experimental data. For SP calculations, we varied FWHM between 0.1 and $1.5 \mathrm{eV}$ to achieve the best agreement with experimental spectra.

MD was carried out in the NVT ensemble using a time step of 1.93 fs. A Nosé-Hoover thermostat (Nosé, 1984; Hoover, 1985 ) with a target temperature of $300 \mathrm{~K}$ and a characteristic time of 120 fs was used to generate a NVT/Boltzmann ensemble of structures. This was achieved by coupling nuclear motion to a fictitious heat bath. For sufficiently long trajectories, this thermostat has been shown to accurately reproduce macroscopic thermodynamic properties (Frenkel and Smit, 2001). The total simulation time of each trajectory amounts to $20 \mathrm{ps}$; 200 single point TDDFT spectra calculations were performed with geometries randomly selected from the MD trajectory.

\section{Results and discussion}

\subsection{Experiments on aqueous photolysis of glyceraldehyde}

Approximately $5 \%$ of all glyceraldehyde molecules remain in the free form at $25^{\circ} \mathrm{C}$ in a dilute solution, and the remaining $95 \%$ form a monohydrate (Glushonok et al., 1986). Three aqueous quantum yield experiments were conducted by photolyzing glyceraldehyde as described in the "Materials and methods" section. We found the average quantum yield of glyceraldehyde to be approximately $0.006 \pm 0.003$ (i.e., less than $1 \%$ of the free glyceraldehyde that absorb photons actually break). The average quantum yield may be slightly elevated in cloud droplets as a higher fraction of molecules would reside at the air/water interface relative to our bulk measurements. Photolysis occurring at the air/water interface can be more efficient than in bulk due to an incomplete solvent molecule cage (Nissenson et al., 2010). Kinetic details of these experiments are presented in the SM Sects. 4 and 5. With Fourier transform infrared (FTIR) spectroscopy, we detected evidence of gaseous carbon monoxide, an expected product of the Norrish type-I splitting. Ethanal and glycolaldehyde, also expected products of photolysis, and several unconfirmed products were identified with ESI-MS. A mass spectrum identifying the presence of these products and a pathway leading to these products are presented in Fig. S8.

Encinas et al. (1985) report that the aqueous quantum yield of dihydroxyacetone at $313 \mathrm{~nm}$ is approximately unity, much larger than the value measured for glyceraldehyde. We use this example to stress that quantum yields can vary drastically, even for isomeric compounds with similar functionality. The difference in quantum yields may be attributed to differences in the chemical mechanism upon exposure to UV light. The dominant step in dihydroxyacetone photolysis is likely cleavage into molecules that do not appreciable combine. However, photolysis of glyceraldehyde may form fragments that subsequently react and revert back to glyceraldehyde (or an aldehydic structural isomer that is indistinguishable from glyceraldehyde using ESI-MS). The expected mechanism for the photolysis of glyceraldehyde is shown in Fig. S28.

\subsection{Role of photolysis in aqueous processing of carbonyls}

In view of the large difference between photolysis quantum yields for isomeric compounds, we can only assume that unknown quantum yields can be anywhere between null (no photolysis) and unity (100\% efficient photolysis). To determine the potential importance of aqueous photolysis processes from the parameters $Z$ and $Q$ defined above, we use the maximum possible value of the photolysis yield, $\Phi=\Phi_{\max }=1$. We will also use a cloud liquid water content of $0.5 \mathrm{~g} \mathrm{~m}^{-3}$, typically the largest value routinely measured 

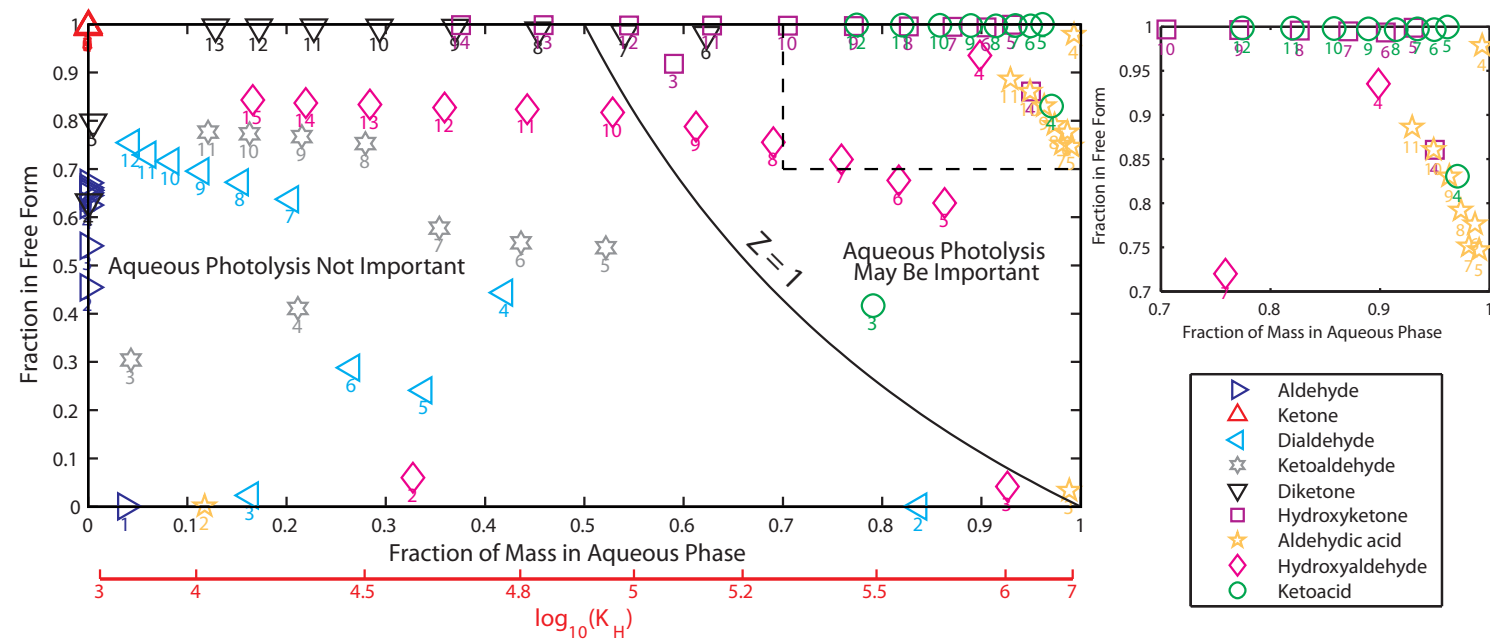

Fig. 2. Fraction of carbonyl compound in the aqueous phase at equilibrium as a function of the fraction of carbonyl compound in the free form for linear-chain compounds in an air mass with a liquid water content of $0.5 \mathrm{~g} \mathrm{~m}^{-3}$. The logarithmic effective Henry's law constant is shown as a secondary $x$ axis in red. Numbers below the symbols indicate the total number of carbon atoms in the molecule. Hydration equilibrium constants and effective Henry's law constants are obtained from experimental data or computational predictions as explained in the Sect. 2.2. Molecules to the left of the $Z=1$ line have gaseous photolysis rates that exceed the aqueous photolysis rates. Molecules to the right of the $Z=1$ line indicate that specified molecules may have aqueous photolysis rates that exceed gas-phase photolysis rates. The upper-right figure is an expanded version of the main figure with limits indicated by the black dashed lines.

in the troposphere (Seinfeld and Pandis, 1998; Hobbs, 1993). In certain instances, liquid water content (LWC, mass of liquid water per volume of air) values of extremely wet clouds can exceed $0.5 \mathrm{~g} \mathrm{~m}^{-3}$, but this typical upper limit provides for a more realistic analysis. The actinic flux is predicted with the Tropospheric Ultraviolet and Visible (TUV) radiation model (Edition 4.4) at a solar zenith angle (SZA) of $20^{\circ}$ with a globally averaged surface albedo of 0.154 from Hummel and Reck (1979). Note that we do not model the effect of the cloud on the actinic flux, so these calculations may not apply in the interior of the cloud, where the flux can be quite different.

Figure 2 details the potential significance of aqueous photolysis for a series of compounds with various functional groups on a carbon backbone. In all the molecules chosen for this study, aldehyde, hydroxyl, and carboxyl groups occupy the terminal positions, and keto groups occupy the 2position in the chain. If two functional groups are present, they are positioned on the opposite ends of the chain (e.g., C8 diketone corresponds to octane-2,7-dione). We choose these series of molecules to systematically investigate how different functional groups and molecular chain lengths affect the relevant chemical properties. Structures of the first three molecules in each series are shown in Table S2. Compounds that lie along the $Z=1$ line have aqueous photolysis removal rates that are at most equal to their corresponding gaseous photolysis rates. Removal due to aqueous photolysis should not be important for compounds that lie to the left of the $Z=1$ isopleth (because they are not soluble enough). For compounds located to the right of the $Z=1$ isopleth, aqueous photolysis may be a significant sink depending on the actual unknown photolysis yields and the competition between the reaction with $\mathrm{OH}$ and photolysis. Figure 2 graphically illustrates that compounds with low effective Henry's law constants and large extents of hydration are not appreciably removed by direct aqueous photolysis. Aqueous photolysis is potentially competitive with gaseous photolysis for certain multifunctional carbonyls. For a given family of compounds, increasing the carbon chain length tends to suppress effective Henry's law constants as the molecules become less polar and thus more hydrophobic. Hydration becomes less favorable as chain length increases.

Atmospheric photooxidation can generate multifunctional, water-soluble compounds that contain more than two functional groups. Figure 3 indicates the potential importance of aqueous photolysis from a selection of photolabile organic compounds generated from isoprene photooxidation (Fang et al., 2012) and limonene photooxidation (Jaoui et al., 2006).

We conclude that some of the photolabile compounds formed in isoprene and d-limonene oxidation have effective Henry's law constants and hydration equilibrium constants such that aqueous photolysis may be an important sink.

The branching ratio $Z$ allows us to eliminate compounds that have gaseous photolysis removal rates that exceed aqueous photolysis removal rates $(Z>1)$. However, a low value of $Z$ does not necessarily imply that photolysis is the primary sink in the aqueous phase; the photolysis lifetime might be too long relative to the lifetime of a typical cloud to be atmospherically relevant and/or it may not be able to compete with oxidation by $\mathrm{OH}$. As in the previous analysis (Sect. 2.3), 


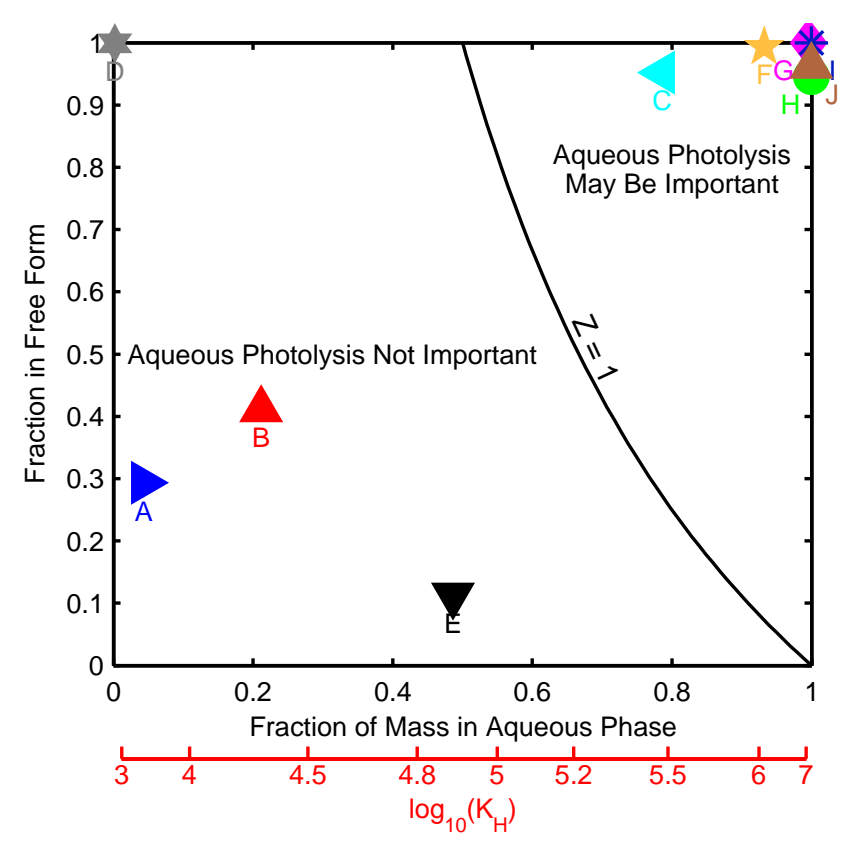

Fig. 3. Hydration equilibrium vs. the fraction of total mass residing in the aqueous phase at equilibrium for photolabile compounds formed from isoprene (Fang et al., 2012) and limonene (Jaoui et al., 2006) photooxidation. Liquid water content is $0.5 \mathrm{~g} \mathrm{~m}^{-3}$. (A) methylglyoxal, (B) 4-hydroxybut-3-en-2-one (assumed to be all 3-oxobutanal after keto-enol equilibrium (Cederstav and Novak, 1994)), (C) pyruvic acid, (D)1-hydroxy-3-methyl-but-3-en-2-one, (E) 2-methyl-2-oxidanyl-propanedial, (F) 4-hydroxy-3-methyl-but2-enal, (G) levulinic acid, (H) 3,6-oxoheptanoic acid, (I) ketonorlimonic acid, (J) ketolimonaldehyde. Structures, effective Henry's law constants, and hydration equilibrium constants are presented in Tables S6 and S7.

the lack of experimental aqueous quantum yield measurements prevents us from directly calculating the photolysis lifetime and the branching ratio $Q$ between the rates of oxidation and photolysis. However, we can use the upper-bound quantum yield value $\left(\Phi=\Phi_{\max }=1\right)$ in order to calculate the maximum possible rate of aqueous photolysis compared to aqueous oxidation. Experimental extinction coefficients as a function of wavelength are also not available for most compounds, and therefore we parameterize the carbonyl peak as purely a function of $\varepsilon_{\max }$ and $\lambda_{\max }$ as described in Sect. 2.3. Aqueous photolysis lifetime at a solar zenith angle of $20^{\circ}$ as described with Eqs. (11) and (12) as a function of $\lambda_{\max }$ and the product $\langle\Phi\rangle \cdot \varepsilon_{\max }$ is plotted in Fig. 4 .

Photolysis lifetime decreases as $\lambda_{\max }$ and/or $\varepsilon_{\max }$ increase due to enhanced overlap with the actinic spectrum. Markers indicate the predicted minimum photolysis lifetime $\left(\Phi_{\max }=1\right)$ for several carbonyl compounds with published values of $\lambda_{\max }$ and $\varepsilon_{\max }$. Figure 4 illustrates that compounds with large quantum yields will have appreciably short, atmospherically relevant photolysis lifetimes in the aqueous phase. Note that these photolysis lifetimes refer to an artifi- cial scenario of a fixed solar zenith angle $\left(\mathrm{SZA}=20^{\circ}\right)$; since photolysis can only occur during daylight hours, the actual lifetimes will be longer.

Conjugation can shift the carbonyl peak to the red and increase its intensity (Pavia, 2009), yielding a shorter atmospheric lifetime. This effect is obvious in Fig. 4 if one compares the lifetimes of propanal and its $\alpha, \beta$-unsaturated analog acrolein, butanal and its $\alpha, \beta$-unsaturated analog crotonaldehyde, and 2-butanone and its $\alpha, \beta$-unsaturated analog methyl vinyl ketone. In all cases, the presence of the $\alpha, \beta$-double bond next to the carbonyl group decreases the lifetime by about an order of magnitude.

For specific carboxylic acids, changes in pH may modify molar extinction coefficients and quantum yields. Pyruvic acid, an $\alpha$-keto carboxylic acid with interaction between the dissociating acid and absorbing carbonyl group, does not exhibit a significant change in absorption between the acid and anion form (Fischer and Warneck, 1991). On the contrary, the quantum yields of pyruvic acid and pyruvate are drastically different (Leermakers and Vesley, 1963), but this fact does not affect our analysis designed to calculate the upper limit of aqueous photolysis with $\Phi_{\max }=1$.

For the carbonyls shown in Fig. 4, aqueous photolysis may occur on atmospherically relevant timescales. However, in order for removal due to aqueous photolysis to be significant, it must compete with other aqueous processes. We can compare aqueous photolysis lifetime with the lifetime due to aqueous oxidation by $\mathrm{OH}$ using Eq. (8). We assume an aqueous $\mathrm{OH}$ concentration of $10^{-13} \mathrm{M}$, reflective of the daytime value recommended in the review by Ervens et al. (2011). This assumed aqueous $\mathrm{OH}$ concentration was predicted with theoretical models in Ervens and Volkamer (2010) and Ervens et al. (2003a), and is similar to the recommended values in Gelencser and Varga (2005) and Vione et al. (2006). However, uncertainties in these predicted aqueous $\mathrm{OH}$ concentrations may be significant. Figure 5 illustrates the competition between these two processes.

Aqueous photolysis is favored for compounds with low $k_{\mathrm{OH}}$ values, strong absorption at high wavelengths, and larger photolysis quantum yields. For compounds that react at the diffusion limit $\left(k_{\mathrm{OH}} \sim 10^{10} \mathrm{M}^{-1} \mathrm{~s}^{-1}\right)$, aqueous oxidation by $\mathrm{OH}$ will exceed aqueous photolysis for all known non-conjugated carbonyls because they are typically characterized by $\lambda_{\max }$ between 260 and $320 \mathrm{~nm}$ and $\varepsilon_{\max }<25 \mathrm{M}^{-1} \mathrm{~cm}^{-1}$. The rate constant for the aqueous oxidation by $\mathrm{OH}$ radical has to be lower than $k_{\mathrm{OH}}=10^{8.5} \mathrm{M}^{-1} \mathrm{~s}^{-1}$ in order for the direct photolysis to become competitive. A similar calculation carried out for levulinic and pyruvic acid at a $\mathrm{pH}$ of 6 , where they react faster with $\mathrm{OH}$, exhibits the same behavior (see Fig. S15). Out of the compounds presented in Fig. 5, only pyruvic acid, methylglyoxal, and glyoxal may have aqueous photolysis rates that exceed the rates of aqueous oxidation by $\mathrm{OH}$.

While the presence of $\alpha, \beta$-unsaturation may increase the rate of aqueous photolysis relative to an 


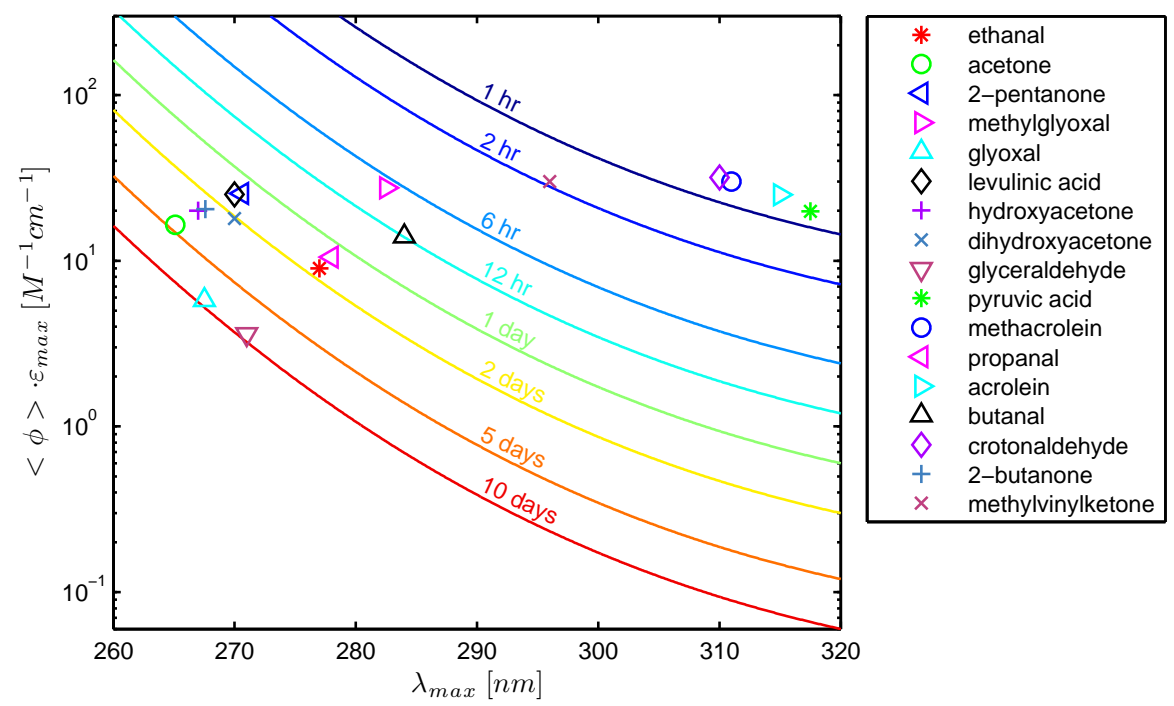

Fig. 4. Predicted aqueous photolysis lifetimes as a function of the wavelength of maximum absorbance of the carbonyl peak and the product of the average photolysis yield and the maximum extinction coefficient of said peak at a solar zenith angle of $20^{\circ}$. Marker positions are determined by experimental values of $\lambda_{\max }$ and $\varepsilon_{\max }$. Note that, in the case of methylglyoxal (Staffelbach et al., 1995) and glyoxal (Horowitz et al., 2001), the $425 \mathrm{~nm}$ band, which is assumed not to contribute to photolysis in water, will potentially reduce photolysis lifetimes compared to the values represented in the figure.

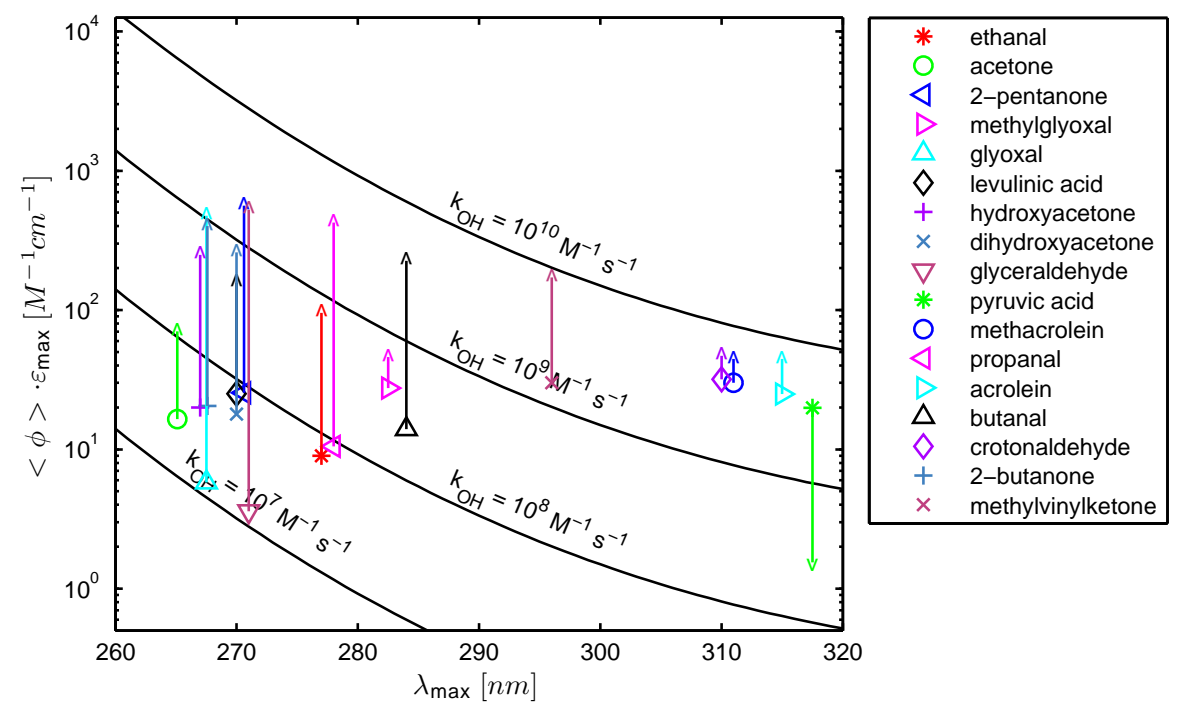

Fig. 5. Comparison of aqueous photolysis at a solar zenith angle of $20^{\circ}$ and aqueous oxidation by $\mathrm{OH}$ at a typical daytime concentration of $10^{-13} \mathrm{M}$ and a $\mathrm{pH}$ of 2 . Molecules, denoted by the markers in the key, have arrows that point to their corresponding $k_{\mathrm{OH}}$. $k_{\mathrm{OH}}$ isopleths correspond to $\lambda_{\max }$ and $\varepsilon_{\max } \cdot<\Phi>$ values, which produce $Q=1$. Molecules with values of $\lambda_{\max }$ and $\varepsilon_{\max } \cdot<\Phi>$ that are below their corresponding $k_{\mathrm{OH}}$ value will be preferentially removed with oxidation by $\mathrm{OH}$ (all of the molecules in this figure except for pyruvic acid). Conversely, molecules with values of $\lambda_{\max }$ and $\varepsilon_{\max } \cdot\langle\Phi\rangle$ that are above their corresponding $k_{\mathrm{OH}}$ value will be preferentially removed by aqueous photolysis. Similar to Fig. 4, the $425 \mathrm{~nm}$ band of methylglyoxal and the 425, 440, and 455 bands of glyoxal will potentially allow for photolysis lifetimes that are shorter than the values represented in the figure if it contributes to aqueous photolysis.

unsaturated analog, the rate of oxidation by $\mathrm{OH}$ is usually faster for the unsaturated compounds. For example, $k_{\mathrm{OH}}(2$-propenal $\quad$ acrolein] $)=7 \times 10^{9} \mathrm{M}^{-1} \mathrm{~s}^{-1}$ and $\quad k_{\mathrm{OH}}($ propanal $)=2.2 \times 10^{9} \mathrm{M}^{-1} \mathrm{~s}^{-1} ; \quad k_{\mathrm{OH}}(2-$ butenal $\quad[$ crotonaldehyde] $)=5.8 \times 10^{9} \mathrm{M}^{-1} \mathrm{~s}^{-1}$ and
$k_{\mathrm{OH}}($ butanal $)=3.9 \times 10^{9} \mathrm{M}^{-1} \mathrm{~s}^{-1} ; \quad k_{\mathrm{OH}}$ (but-3-en-2-one [methyl vinyl ketone] $)=8.5 \times 10^{9} \mathrm{M}^{-1} \mathrm{~s}^{-1}$ and $k_{\mathrm{OH}}(2-$ butanone) $=9.0 \times 10^{8} \mathrm{M}^{-1} \mathrm{~s}^{-1}$ (Monod et al., 2005; Buxton et al., 1988). The enhanced absorption cross sections of these unsaturated compounds are partially balanced out 


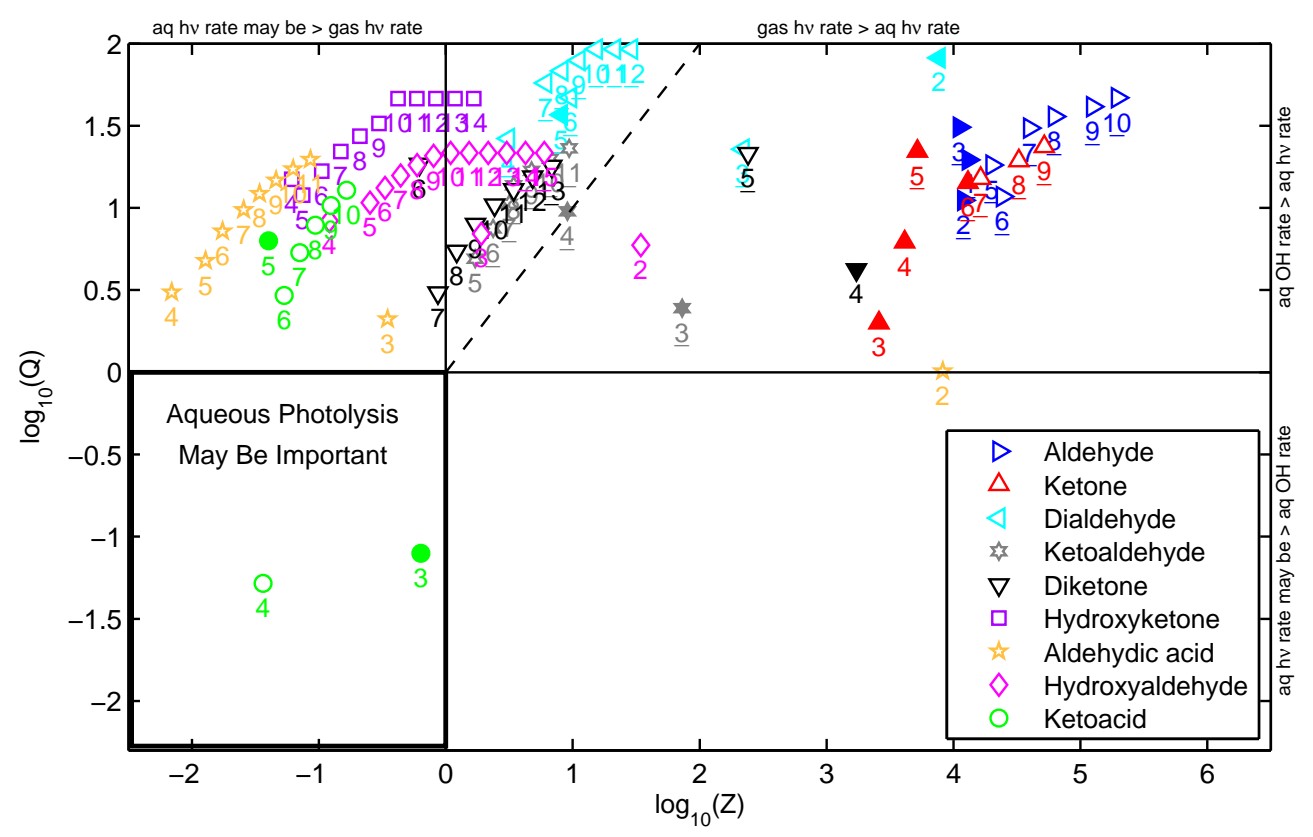

Fig. 6. Branching ratio between aqueous oxidation by $\mathrm{OH}$ radicals and aqueous photolysis $Q=\frac{\mathrm{d} n_{\mathrm{OH}}^{\mathrm{aq}}}{\mathrm{d} t} / \frac{\mathrm{d} n_{h v}^{\mathrm{aq}}}{\mathrm{d} t}$ vs. branching ratio between gaseous photolysis and aqueous photolysis $Z=\frac{\mathrm{d} n_{h v}^{\text {gas }}}{\mathrm{d} t} / \frac{\mathrm{d} n_{h v}^{\mathrm{aq}}}{\mathrm{d} t}$ for the series of compounds presented in Fig. 2 in an air mass with $\mathrm{LWC}=0.5 \mathrm{~g} \mathrm{~m}^{-3}$, an aqueous $\mathrm{OH}$ concentration of $10^{-13} \mathrm{M}$ at a solar zenith angle of $20^{\circ}$. All aqueous photolysis quantum yields are assumed to be at their upper limit $(\Phi=1)$. Molecules notated with filled markers indicate that published $\lambda \max$ and $\varepsilon_{\max }$ values were used to calculate extinction coefficients. Open markers indicate that extinction coefficients were determined with estimations of $\lambda_{\max }$ and $\varepsilon_{\max }$ from compounds with similar functional groups. Numbers corresponding to each symbol indicate the number of carbon molecules in the chain. Underlined numbers indicate that gas-phase oxidation by $\mathrm{OH}$ is the dominant removal mechanism. Rate constants, hydration equilibrium constants, Henry's law constants, structures, names, and all corresponding references are presented in the SM Sect. 19 . The $Q=Z$ line is shown as a dashed line in the upper-right quadrant.

by the enhanced rate of $\mathrm{OH}$ oxidation, leading to aqueous removal rates still dominated by $\mathrm{OH}$ oxidation.

We can compare the maximum rate of aqueous photolysis $\left(\Phi_{\max }=1\right)$ with the rate of aqueous oxidation by $\mathrm{OH}$ radical with help of rate constant predictions using structure activity coefficients. All predicted rate constants were capped at the diffusion controlled limit of $10^{10} \mathrm{M}^{-1} \mathrm{~s}^{-1}$ (Vione et al., 2006). Complete extinction coefficients across all actinic wavelengths were not available for most compounds, but published values of $\lambda_{\max }$ and $\varepsilon_{\max }$ are available for many carbonyl compounds (Xu et al., 1993; Malik and Joens, 2000; Steenken et al., 1975; Hammond et al., 1959; Mackinney and Temmer, 1948; Schutze and Herrmann, 2004; Rice, 1920; Gubina et al., 2004). For simple mono- and di-carbonyl compounds without published $\lambda_{\max }$ and $\varepsilon_{\max }$ values (76 out of 92 total compounds), we made educated upper estimates based on the values of compounds with similar functionality. In order to determine the compounds that may be significantly removed with aqueous photolysis, we also must consider the magnitude of the branching ratio $Z$ in our analysis. Specifically, aqueous photolysis is only potentially important for compounds with $Q<1$ (the rate of removal due to aqueous photolysis is potentially greater than the rate of removal due to aqueous oxidation by $\mathrm{OH}$ radical) and $Z<1$ (the rate of removal due to aqueous photolysis is potentially greater than the rate of removal due to gaseous photolysis).

Figure 6 illustrates both of these branching ratios for the same series of carbonyl compounds as presented in Fig. 2 at a solar zenith angle of $20^{\circ}$ in an air mass with a liquid water content of $0.5 \mathrm{~g} \mathrm{~m}^{-3}$ at $25^{\circ} \mathrm{C}$. The upper-right quadrant of Fig. 6 contains molecules for which aqueous photolysis is slower than both gaseous photolysis and aqueous oxidation by $\mathrm{OH}$. The upper-left quadrant contains molecules for which aqueous photolysis may be faster than gaseous photolysis, but removal by $\mathrm{OH}$ is still the dominant sink in the aqueous phase. Pyruvic acid [2-oxopropanoic acid] and acetoacetic acid [3-oxobutanoic acid] lie in the lower-left quadrant; for these two compounds, aqueous photolysis may be faster than both gaseous photolysis and aqueous oxidation by $\mathrm{OH}$. The lower-right quadrant shows the bounds of $Z$ and $Q$ where aqueous photolysis rates are faster than aqueous oxidation by $\mathrm{OH}$, but gaseous photolysis exceeds the rate of aqueous photolysis. Molecules that have gaseous $\mathrm{OH}$ oxidation rates that exceed the removal rates of the other three 
sinks are notated with underlined numbers. Gas-phase oxidation by $\mathrm{OH}$ is dominant for many molecules in the upperright quadrant.

In this series of carbonyl compounds, only pyruvic acid and acetoacetic acid may be preferentially removed by aqueous-phase photolysis. These compounds have sufficiently high effective Henry's law constants, do not hydrate completely in the aqueous phase, and have predicted $k_{\mathrm{OH}}$ values significantly less than the diffusion controlled limit $\left(7.0 \times 10^{8} \mathrm{M}^{-1} \mathrm{~s}^{-1}\right.$ and $2.7 \times 10^{8} \mathrm{M}^{-1} \mathrm{~s}^{-1}$, respectively). Methylglyoxal (Staffelbach et al., 1995), biacetyl (Schutze and Herrmann, 2004), and glyoxal (Horowitz et al., 2001) have an additional $\pi^{*} \leftarrow n$ absorption band in the vicinity of $400-500 \mathrm{~nm}$ that is not captured with this parameterization. Therefore, the $Q$ values of these compounds may be lower than the plotted values. However, gas-phase processes still dominate the removal of these three compounds.

To help compare rates of gas-phase photolysis and aqueous $\mathrm{OH}$ reaction, the $Q=Z$ line is shown as a dashed line in the upper-right quadrant of Fig. 6. Molecules to the right of this line within this quadrant have gas-phase photolysis rates that exceed rates of aqueous oxidation by $\mathrm{OH}$. The mono-aldehydes and mono-ketones lie completely in this region along with some of the smaller multifunctional compounds. The small Henry's law constants and/or hydration equilibrium constants of these molecules ensure that gasphase processes will dominate. Molecules to the left of the $Q=Z$ line within this quadrant have rates of aqueous oxidation by $\mathrm{OH}$ that exceed the gas-phase photolysis rates. The majority of the multifunctional compounds lie in this region. These multifunctional compounds generally have enhanced Henry's law constants that increase solubility and encourage aqueous processing.

Uncertainties in the prediction of $Z$ and $Q$ arise from using estimates of $K_{H}, K_{\mathrm{hyd}}, k_{\mathrm{OH}}$, and $p K_{\mathrm{A}}$ where experimental data was not available. The uncertainties in $Z$ and $Q$ for the carbonyl compounds examined in Fig. 6 are represented as error bars in Fig. S29. While some compounds have large uncertainty bounds, the majority of compounds have uncertainties that are less than an order of magnitude in $Z$ and $Q$. None of the compounds have uncertainty bounds large enough to alter the conclusions that we draw from Fig. 6 . Uncertainties also arise from parameterizing the extinction coefficients as a function of $\lambda_{\max }$ and $\varepsilon_{\max }$. A comparison of $Q$ calculated with published extinction coefficients and $Q$ calculated with our parameterization is presented in Fig. S14. For compounds without published extinction coefficients, estimates of $\lambda_{\max }$ and $\varepsilon_{\max }$ from compounds with similar functionality are another source of uncertainty. We used upperbound estimates to continue with the theme of calculating maximum aqueous photolysis rates to eliminate compounds with uncompetitive rates.

We also investigated the sensitivity of $Z$ and $Q$ under different atmospheric conditions. Figure S11 details the effects of a lower LWC of $0.05 \mathrm{~g} \mathrm{~m}^{-3}$, Fig. S9 uses a SZA of $0^{\circ}$,

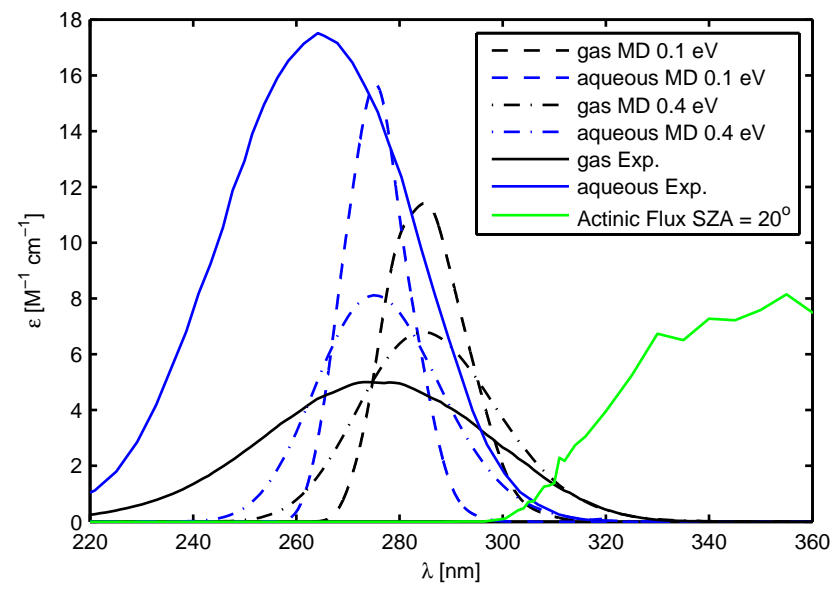

Fig. 7. Comparison of published aqueous- (Xu et al., 1993) and gasphase acetone spectra (Sander et al., 2011) with spectra calculated using MD simulations. Gas and aqueous absorption cross sections were calculated with a $0.1 \mathrm{eV}$ and $0.4 \mathrm{eV}$ Gaussian broadening. The solar actinic flux at a solar zenith angle of $20^{\circ}$ is also shown for comparison.

Fig. S12 shows how $\mathrm{pH}$ affects $Z$ and $Q$ values, and Fig. S10 was calculated at a lower-limit aqueous $\mathrm{OH}$ concentration of $2.5 \times 10^{-14} \mathrm{M}$. (A full discussion of these figures is presented in the SM Sect. 6.) Several additional compounds may have significant rates of aqueous photolysis at an aqueous $\mathrm{OH}$ concentration of $2.5 \times 10^{-14} \mathrm{M}$ (heptane-2,6-dione, 3oxopropanoic acid, 4-oxobutanoic acid, and 5-oxohexanoic acid). However, besides these compounds, the chemical behavior at the limits of typical atmospheric conditions remains generally unchanged.

\subsection{Computational chemistry predictions of spectroscopic properties of compounds in d-limonene and isoprene SOA}

To predict the importance of aqueous photolysis for compounds where no spectroscopic data are available, we computed the vibronic absorption spectrum using timedependent density functional theory (TDDFT). To assess the accuracy of this approach we first computed the absorption spectra of several reference molecules in the gas phase and in solution (Table 1). We then used this approach to predict absorption spectra for several complex atmospherically relevant SOA compounds for which no experimental data are available.

$\lambda_{\max }$ values for the gas phase are similarly accurate for SP calculations and MD calculations, exhibiting mean absolute errors (MAE) of 12.3 and $12.4 \mathrm{~nm}$, respectively. In solution, MAE amount to 9.7 and $12.0 \mathrm{~nm}$ for SP and MD calculations, respectively.

An important result of this work is that the extinction coefficients from the SP calculations are in most cases significantly smaller compared to the MD simulations, irrespective 
Table 1. Calculated wavelength of maximum absorption $\lambda_{\max }(\mathrm{nm})$ and decadic molar absorption coefficients $\varepsilon_{\max }\left(\mathrm{M}^{-1} \mathrm{~cm}^{-1}\right) \mathrm{of}_{\mathrm{me}}$ reference compounds. Only the absorption band closest to $280 \mathrm{~nm}$ is reported. In cases where two absorption peaks were predicted in the $280 \mathrm{~nm}$ region, both values are reported. MD denotes that the spectra have been computed by averaging over several structures obtained from MD simulations. Values of FWHM used to calculate the molar absorption coefficients are reported in parentheses. Subscripted numbers indicate the references used for the experimental parameters: Ref. 1 (Horowitz et al., 2001), Ref. 2 (Xu et al., 1993), Ref. 3 (Mackinney and Temmer, 1948), Ref. 4 (Chen et al., 2000), Ref. 5 (Schutze and Herrmann, 2004), Ref. 6 (Martinez et al., 1975), and Ref. 7 (Bayrakçeken, 2007). Aqueous $\lambda_{\max }$ and $\varepsilon_{\max }$ of glyceraldehyde were obtained from this work. A full set of computed spectra and structures of these compounds are shown in Figs. S18-S27.

\begin{tabular}{|c|c|c|c|c|c|c|c|}
\hline & & \multicolumn{3}{|c|}{$\lambda_{\max }[\mathrm{nm}]$} & \multicolumn{3}{|c|}{$\varepsilon_{\max }\left[\mathrm{M}_{-1} \mathrm{~cm}_{-1}\right]$} \\
\hline & & SP calculated & MD calculated & Exper. & SP calculated & MD calculated & Exper. \\
\hline \multirow[t]{2}{*}{ acetone [2-propanone] } & Gaseous & 283 & 285 & $275_{1}$ & 0.04 & 11.4 & $5.0_{1}$ \\
\hline & Aqueous & 273 & 275 & $264_{2}$ & 0.02 & 15.7 & $13.7_{2}$ \\
\hline \multirow[t]{2}{*}{ levulinic acid [4-oxopentanoic acid] } & Gaseous & 279 & 282 & n.a. & 13.9 & 97.4 & n.a. \\
\hline & Aqueous & 271 & 281 & $270_{3}$ & 13.9 & 54.7 & $25.1_{3}$ \\
\hline \multirow[t]{2}{*}{ methylglyoxal [2-oxopropanal] } & Gaseous & 279 & $283 / 298$ & 2864 & 6.1 & $13.0 / 12.5$ & 12.84 \\
\hline & Aqueous & 281 & $276 / 291$ & $284_{5}$ & 6.2 & $24.8 / 27.1$ & $16_{5}$ \\
\hline \multirow[t]{2}{*}{ 3-oxobutanal } & Gaseous & 289 & $285 / 305$ & n.a. & $37.1(1.5 \mathrm{eV})$ & $91.3 / 310.1$ & n.a. \\
\hline & Aqueous & 281 & $278 / 302$ & $280_{6}$ & $75.6(0.7 \mathrm{eV})$ & $130.9 / 306.7$ & $10_{6}$ \\
\hline \multirow[t]{2}{*}{ 2,3-butanedione [biacetyl] } & Gaseous & 275 & 278 & $290_{7}$ & 0.2 & $5.0_{7}$ & n.a \\
\hline & Aqueous & 269 & 271 & $284_{5}$ & 0.3 & $12.0_{5}$ & 26.3 \\
\hline \multirow[t]{2}{*}{ pyruvic acid [2-oxo-propanoic acid] } & Gaseous & 369 & 374.6 & $350_{1}$ & $4.1(0.2 \mathrm{eV})$ & 14.2 & $11.7_{1}$ \\
\hline & Aqueous & 353.2 & 353.4 & $317.5_{3}$ & 3.8 & 11.1 & $19.5_{3}$ \\
\hline \multirow[t]{2}{*}{ Glyceraldehyde [2,3-dihydroxypropanal] } & Gaseous & 274 & 275 & n.a. & 423.5 & 158.1 & n.a. \\
\hline & Aqueous & 268 & 268 & 271 & $64.2(0.6)$ & 136.9 & 3.7 \\
\hline
\end{tabular}

of the broadening due to the neglect of vibrational effects in SP calculations (Table 1). These effects can be particularly strong for small symmetric systems such as acetone or 2,3-butanedione. The symmetry breaking occurring during MD is necessary to predict extinction coefficients more accurately. For the aqueous SP values with individually adjusted Gaussian broadening, we find an MAE of $28.9 \mathrm{M}^{-1} \mathrm{~cm}^{-1}$; however these individually adjusted SP calculations are empirical. The MAE of the aqueous MD calculations is slightly larger $\left(45.3 \mathrm{M}^{-1} \mathrm{~cm}^{-1}\right)$ when calculated using a constant broadening of $0.1 \mathrm{eV}$. 3-oxobutanal and glyceraldehyde appear to be outliers. Aqueous MD calculations overestimate their extinction coefficients by $120.9 \mathrm{M}^{-1} \mathrm{~cm}^{-1}$ and $133.2 \mathrm{M}^{-1} \mathrm{~cm}^{-1}$, respectively, while aqueous SP calculations overestimate their extinction coefficients by $65.6 \mathrm{M}^{-1} \mathrm{~cm}^{-1}$ and $60.5 \mathrm{M}^{-1} \mathrm{~cm}^{-1}$, respectively. If we exclude 3-oxobutanal and glyceraldehyde, aqueous MD calculations lead to a smaller MAE $\left(12.6 \mathrm{M}^{-1} \mathrm{~cm}^{-1}\right)$ than aqueous $\mathrm{SP}$ calculations $\left(15.3 \mathrm{M}^{-1} \mathrm{~cm}^{-1}\right)$.

A comparison of the acetone aqueous- and gas-phase spectrum is presented in Fig. 7. The computed spectra of the molecules investigated over all relevant wavelengths are presented in the SM (Figs. S18-S27). For some compounds, the applied broadening of $0.1 \mathrm{eV}$ leads to spectra with more vibrational fine structure than found in the published experiments. As in the case of acetone, we observe a blue shift for all compounds except for pyruvaldehyde when the solvent is included in the calculation. In most cases, inclusion of the solvent leads to decreased aqueous photolysis rate be- cause of the decreased overlap between the absorption band and the actinic flux (and likely due to the quantum yield suppression, which we do not consider in this paper). The selected FWHM values also affect the calculated rates. Without an explicit treatment of the vibrational structure (Dierksen and Grimme, 2004), TDDFT bandwidths can only approximate the envelope of the vibrational fine structure, leading to potentially significant errors in the resulting photolysis rate. In the case of the aqueous absorption spectrum of acetone (Fig. 7), a FWHM of $0.4 \mathrm{eV}$ leads to an increased overlap between the absorption band and the actinic flux, resulting in a photolysis rate 450 times larger than that of a FWHM of $0.1 \mathrm{eV}$. (Our uncertainty is smaller as we parameterize absorption peaks with $\lambda_{\max }, \varepsilon_{\max }$, and a FWHM determined experimentally from similar compounds.) Computational tools to accurately predict absorption peak width along with wavelength-dependent intensity are presently too computationally expensive for large-scale applications.

Keeping these (potentially very large) uncertainties in mind, we applied this method to compute the spectra of several relevant photolabile compounds identified in d-limonene (Jaoui et al., 2006) and isoprene (Fang et al., 2012) SOA. These four carbonyl-containing compounds, 4-hydroxy-3methyl-but-2-enal, 3,6-oxoheptanoic acid, ketolimononaldehyde, and ketonorlimonic acid, do not have published aqueous extinction coefficients. Computationally derived spectra and $\varepsilon_{\max }$ and $\lambda_{\max }$ values are presented in the SM Sects. 11 and 12. Cautious application of these computational parameters reveals important information about the significance of 
aqueous photolysis for these compounds even when taking the large uncertainties into account. In Fig. S29, we compare the rates of aqueous oxidation by $\mathrm{OH}$ to the maximum rate of aqueous photolysis determined with calculated $\varepsilon_{\max }$ and $\lambda_{\max }$ values. Even after taking into account the MAE of the MD simulations, ketolimonaldehyde absorbs strongly enough such that aqueous photolysis may be more important than aqueous oxidation by $\mathrm{OH}$. All four compounds have $Z$ values that are less than unity (aqueous photolysis may be faster than gaseous photolysis; see Fig. 3). However, the large MAE of the MD simulations leads to ambiguity in determining the dominant removal sink of 4-hydroxy-3-methyl-but2-enal, 3,6-oxoheptanoic acid, and ketonorlimonic acid. A significant improvement in computational accuracy is clearly needed to determine the atmospheric fate of these important compounds. With rapid, on-going development of TDDFT methods, more realistic calculations of photophysical properties of atmospherically relevant multifunctional compounds should become possible in the near future.

\subsubsection{Atmospheric implications}

Under typical atmospheric conditions, aqueous photolysis is not likely to be a significant atmospheric sink of the relatively simple carbonyls investigated in this manuscript. There are important exceptions to this rule including pyruvic acid and acetoacetic acid; we note that aqueous photolysis experiments of pyruvic acid are well established in the literature (Leermakers and Vesley, 1963; Larsen and Vaida, 2012; Guzmán et al., 2006; Guzmán et al., 2007). While carbonyls, keto-carboxylic acids, and hydroxyl-carbonyls may readily partition into cloud and fog droplets, once in the aqueous phase, oxidation by dissolved $\mathrm{OH}$ is a more efficient removal process than direct photolysis. $\mathrm{OH}$ oxidation rate constants typically increase for larger compounds as there are more hydrogen atoms available for abstraction. Figures S16 and S17 show predicted $k_{\mathrm{OH}}^{\mathrm{aq}}$ of each chemical family investigated as a function of carbon and hydrogen number, respectively. Only carbonyls with enough oxygen content to enhance solubility containing ketone and/or acid groups (which limit $\mathrm{OH}$ attack), and with few hydrogen atoms available for abstraction by $\mathrm{OH}$, may have significant rates of aqueous photolysis.

Our assertion that the direct photolysis of aqueous carbonyls is generally insignificant may break down in specific cases. Certain molecular functionalities that we have not fully investigated could enhance the rate of aqueous photolysis. Conjugation with $C=C$ double bonds can shift the carbonyl $\pi^{*} \leftarrow n$ transition peak to the red and increase intensity (Pavia, 2009). For example, the types of multifunctional carbonyls found in secondary organic aerosols must have sufficiently high values of $\varepsilon_{\max }$ because they are readily degraded by the direct photolysis. Aqueous photolysis of highly oxygenated aromatic carbonyls may also be important (e.g., for benzaldehyde: $\lambda_{\max } \approx 283, \varepsilon_{\max }=1550 \mathrm{M}^{-1} \mathrm{~cm}^{-1}$ (Sham and Joens, 1995)).
Our analysis assumed a SZA of $20^{\circ}$ and a relatively large LWC. Irradiation at a lower solar zenith angle of $0^{\circ}$ will not significantly affect the results of our analysis. However, cloud and fog droplets with a depleted $\mathrm{OH}$ concentration will enhance the relative contribution of aqueous photolysis processes. If we calculate the branching ratio $Q$ with $\mathrm{C}_{\mathrm{OH}}=2.5 \times 10^{-14} \mathrm{M}$, the lower end of the fair-weather cloud $\mathrm{OH}$ concentration suggested by Vione et al. (2006), we find that aqueous photolysis of 3-oxopropanoic acid, 4-oxobutanoic acid, heptane-2,6-dione, and 5-oxoheptanoic acid may become important in addition to pyruvic acid and acetoacetic acid (see Supplement Fig. S10). However this depressed aqueous $\mathrm{OH}$ radical concentration is unlikely to occur at lower solar zenith angles when both photolysis and production of $\mathrm{OH}$ should be enhanced. Depressed OH concentrations may occur in wetted aerosol particles; however, wetted particles contain significantly less liquid than a cloud or fog droplet, making gas-phase processing of wetted organic particles more likely than aqueous photolysis for the types of molecules considered in this study. Perturbations from Henry's law equilibrium are possible (Finlayson-Pitts and Pitts, 2000; Li et al., 2008; van Pinxteren et al., 2005) and can be interpreted in a shift in the horizontal axis in Fig. 6. Each order of magnitude enhancement in the aqueous-phase concentration of the selected species above the Henry's law equilibrium value will shift its marker one unit to the left. However, perturbations from Henry's law will not affect the behavior of compounds where $\log _{10}(Q)>0$ as the competition between aqueous-phase oxidation by $\mathrm{OH}$ and aqueous photolysis will remain unchanged (because it does not depend on the concentration of dissolved organics as long as the droplet remains sufficiently dilute).

As information on the common carbonyl constituents of particulate matter, cloud droplets, and fog droplets becomes available, the question of the dominant atmospheric fate of these compounds will invariably arise. With limited information about a specific compound (estimates of $K_{H}, K_{\text {hyd }}$, $\lambda_{\max }$, and $\varepsilon_{\max }$ ), the framework presented in this paper will be a useful tool to determine if quantum yield experiments will produce significant results, or should even be carried out in the first place.

\section{Supplementary material related to this article is available online at http://www.atmos-chem-phys.net/13/ 9461/2013/acp-13-9461-2013-supplement.pdf.}

Acknowledgements. The authors acknowledge the National Science Foundation grants AGS-1227579 (S. A. Nizkorodov) and CHE-0909227 (S. A. Epstein, E. Tapavicza, F. Furche) for funding this work.

Edited by: B. Ervens 


\section{References}

Albaladejo, J., Ballesteros, B., Jimenez, E., Martin, P., and Martinez, E.: A PLP-LIF kinetic study of the atmospheric reactivity of a series of C4-C7 saturated and unsaturated aliphatic aldehydes with OH, Atmos. Environ., 36, 3231-3239, 2002.

Albinet, A., Minero, C., and Vione, D.: Photochemical generation of reactive species upon irradiation of rainwater: Negligible photoactivity of dissolved organic matter, Sci. Total Environ., 408, 3367-3373, doi:10.1016/j.scitotenv.2010.04.011, 2010a.

Albinet, A., Minero, C., and Vione, D.: Phototransformation processes of 2,4-dinitrophenol, relevant to atmospheric water droplets, Chemosphere, 80, 753-758, 2010b.

Amyes, T. L. and Richard, J. P.: Enzymatic catalysis of proton transfer at carbon: Activation of triosephosphate isomerase by phosphite dianion, Biochemistry, 46, 5841-5854, doi:10.1021/bi700409b, 2007.

Atkinson, R.: A structure-activity relationship for the estimation of rate constants for the gas-phase reactions of $\mathrm{OH}$ radicals with organic compounds, Int. J. Chem. Kinet., 19, 799-828, doi:10.1002/kin.550190903, 1987.

Atkinson, R., Tuazon, E. C., and Aschmann, S. M.: Atmospheric chemistry of 2-pentanone and 2-heptanone, Environ. Sci. Technol., 34, 623-631, doi:10.1021/es9909374, 2000.

Atkinson, R., Baulch, D. L., Cox, R. A., Crowley, J. N., Hampson, R. F., Hynes, R. G., Jenkin, M. E., Rossi, M. J., and Troe, J.: Evaluated kinetic and photochemical data for atmospheric chemistry: Volume II; gas phase reactions of organic species, Atmos. Chem. Phys., 6, 3625-4055, doi:10.5194/acp-6-3625-2006, 2006.

Bacher, C., Tyndall, G., and Orlando, J.: The atmospheric chemistry of glycolaldehyde, J. Atmos. Chem., 39, 171-189, doi:10.1023/a:1010689706869, 2001.

Bayliss, N. S. and McRae, E. G.: Solvent effects in the spectra of acetone, crotonaldehyde, nitromethane and nitrobenzene, J. Phys. Chem., 58, 1006-1011, doi:10.1021/j150521a018, 1954.

Bayrakçeken, F.: Sensitized phosphorescence studies of p-xylene + biacetyl system, an optical antenna, Spectrochim. Acta A, 66, 1267-1270, doi:10.1016/j.saa.2006.06.018, 2007.

Bell, R. P. and Gold, V.: The reversible hydration of carbonyl compounds, in: Adv. Phys. Org. Chem., Academic Press, 1-29, 1966.

Berger, R., Fischer, C., and Klessinger, M.: Calculation of the vibronic fine structure in electronic spectra at higher temperatures. 1. Benzene and pyrazine, J. Phys. Chem. A, 102, 7157-7167, doi:10.1021/jp981597w, 1998.

Betterton, E. A., and Hoffmann, M. R.: Henry's law constants of some environmentally important aldehydes, Environ. Sci. Technol., 22, 1415-1418, doi:10.1021/es00177a004, 1988.

Bowman, J. H., Barket, D. J., and Shepson, P. B.: Atmospheric chemistry of nonanal, Environ. Sci. Technol., 37, 2218-2225, 2003.

Brown, H. C., McDaniel, D. H., and Hãfliger, O.: Determination of organic structures by physical methods, Dissociation Constants, edited by: Braude, E. A. and Nachod, F. C., v. 1, Academic Press, 1955.

Bunce, N. J., Lamarre, J., and Vaish, S. P.: Photorearrangement of azoxybenzene to 2-hydroxyazobenzene: A convenient chemical actinometer, Photochem. Photobiol., 39, 531-533, doi:10.1111/j.1751-1097.1984.tb03888.x, 1984.

Buschmann, H.-J., Füldner, H.-H., and Knoche, W.: The reversible hydration of carbonyl compounds in aqueous so- lution. Part i, the keto/gem-diol equilibrium, Berichte der Bunsengesellschaft für physikalische Chemie, 84, 41-44, doi:10.1002/bbpc.19800840109, 1980.

Buttery, R. G., Bomben, J. L., Guadagni, D. G., and Ling, L. C.: Volatilities of organic flavor compounds in foods, J. Agric. Food. Chem., 19, 1045-1048, doi:10.1021/jf60178a004, 1971.

Buxton, G. V., Greenstock, C. L., Helman, W. P., and Ross, A. B.: Critical review of rate constants for reactions of hydrated electrons, hydrogen atoms and hydroxyl radicals in aqueous solution, J. Phys. Chem. Ref. Data, 17, 513-886, 1988.

Buxton, G. V., Malone, N. T., and Salmon, G. A.: Oxidation of glyoxal initiated by $\mathrm{OH}$ in oxygenated aqueous solution, J. Chem. Soc., Faraday Trans., 93, 2889-2891, 1997.

Calvert, J. G. and Pitts, J. N.: Photochemistry, Wiley, New York, NY, 625-626, 1966.

Cederstav, A. K. and Novak, B. M.: Investigations into the chemistry of thermodynamically unstable species. The direct polymerization of vinyl alcohol, the enolic tautomer of acetaldehyde, J. Am. Chem. Soc., 116, 4073-4074, doi:10.1021/ja00088a051, 1994.

Chen, J., Peijnenburg, W. J. G. M., Quan, X., and Yang, F.: Quantitative structure property relationships for direct photolysis quantum yields of selected polycyclic aromatic hydrocarbons, Sci. Total Environ., 246, 11-20, 2000.

Dagaut, P., Wallington, T. J., Liu, R., and Kurylo, M. J.: A kinetics investigation of the gas-phase reactions of $\mathrm{OH}$ radicals with cyclic ketones and diones: Mechanistic insights, J. Phys. Chem., 92, 4375-4377, 1988.

Dawson, R. M. C., Elliott, D. C., and Elliott, W. H.: Data for biochemical research, Oxford University Press on Demand, 1989.

Dearden, J. C. and Schüürmann, G.: Quantitative structureproperty relationships for predicting Henry's law constant from molecular structure, Environ. Toxicol. Chem., 22, 1755-1770, doi:10.1897/01-605, 2003.

Dierksen, M. and Grimme, S.: Density functional calculations of the vibronic structure of electronic absorption spectra, J. Chem. Phys., 120, 3544-3554, 2004.

Doussin, J. F. and Monod, A.: Structure-activity relationship for the estimation of $\mathrm{OH}$-oxidation rate constants of carbonyl compounds in the aqueous phase, Atmos. Chem. Phys. Discuss., 13, 15949-15991, doi:10.5194/acpd-13-15949-2013, 2013.

Encinas, M. V., Rufs, A. M., and Lissi, E. A.: Photochemistry of hydroxyalkanones in solution, J. Chem. Soc., Perkin Trans. 2, 457-460, 1985.

EPA HENRYWIN v3.20, US Environmental Protection Agency, 2011.

Epstein, S. A. and Nizkorodov, S. A.: A comparison of the chemical sinks of atmospheric organics in the gas and aqueous phase, Atmos. Chem. Phys., 12, 8205-8222, doi:10.5194/acp-12-82052012, 2012.

Epstein, S. A., Shemesh, D., Tran, V. T., Nizkorodov, S. A., and Gerber, R. B.: Absorption spectra and photolysis of methyl peroxide in liquid and frozen water, J. Phys. Chem. A, 24, 6068-6077, 2012.

Ervens, B. and Volkamer, R.: Glyoxal processing by aerosol multiphase chemistry: Towards a kinetic modeling framework of secondary organic aerosol formation in aqueous particles, Atmos. Chem. Phys., 10, 8219-8244, doi:10.5194/acp-10-82192010, 2010. 
Ervens, B., George, C., Williams, J. E., Buxton, G. V., Salmon, G. A., Bydder, M., Wilkinson, F., Dentener, F., Mirabel, P., Wolke, R., and Herrmann, H.: Capram 2.4 (modac mechanism): An extended and condensed tropospheric aqueous phase mechanism and its application, J. Geophys. Res., 108, 4426, doi:10.1029/2002jd002202, 2003a.

Ervens, B., Gligorovski, S., and Herrmann, H.: Temperaturedependent rate constants for hydroxyl radical reactions with organic compounds in aqueous solutions, Phys. Chem. Chem. Phys., 5, 1811-1824, 2003b.

Ervens, B., Turpin, B. J., and Weber, R. J.: Secondary organic aerosol formation in cloud droplets and aqueous particles (aqSOA): A review of laboratory, field and model studies, Atmos. Chem. Phys., 11, 11069-11102, doi:10.5194/acp-1111069-2011, 2011.

Esposito, A., Lukas, A., Meany, J. E., and Pocker, Y.: The reversible enolization and hydration of pyruvate: Possible roles of keto, enol, and hydrated pyruvate in lactate dehydrogenase catalysis, Can. J. Chem., 77, 1108-1117, doi:10.1139/v99-071, 1999.

Facchini, M. C., Fuzzi, S., Zappoli, S., Andracchio, A., Gelencsér, A., Kiss, G., Krivácsy, Z., Mészáros, E., Hansson, H.-C., Alsberg, T., and Zebühr, Y.: Partitioning of the organic aerosol component between fog droplets and interstitial air, J. Geophys. Res., 104, 26821-26832, doi:10.1029/1999jd900349, 1999.

Fang, W., Gong, L., Zhang, Q., Cao, M., Li, Y., and Sheng, L.: Measurements of secondary organic aerosol formed from $\mathrm{OH}-$ initiated photo-oxidation of isoprene using online photoionization aerosol mass spectrometry, Environ. Sci. Tech., 46, 38983904, doi:10.1021/es204669d, 2012.

Finlayson-Pitts, B. J. and Pitts, J. N.: Chemistry of the upper and lower atmosphere, Academic Press, San Diego, CA, USA, 93$128,2000$.

Fischer, M. and Warneck, P.: The dissociation constant of pyruvic acid: Determination by spectrophotometric measurements, Berichte der Bunsengesellschaft für physikalische Chemie, 95, 523-527, doi:10.1002/bbpc.19910950414, 1991.

Frelek, J., Kowalska, P., Masnyk, M., Kazimierski, A., Korda, A., Woźnica, M., Chmielewski, M., and Furche, F.: Circular dichroism and conformational dynamics of cephams and their carba and oxa analogues, Chem.-Eur. J., 13, 6732-6744, doi:10.1002/chem.200700127, 2007.

Frenkel, D. and Smit, B.: Understanding molecular simulation: From algorithms to applications, Elsevier Science, 153-158, 2001.

Furche, F. and Rappoport, D.: Computational photochemistry, Computational and theoretical chemistry, edited by: Olivucci, M., Elsevier, Amsterdam, 93-128, 2005.

Garcia-Jiminez, F., Zuniga, O. C., Garcia, Y. C., Cardenas, J., and Cuevas, G.: Experimental and theoretical study of the products from the spontaneous dimerization of dl- and d-glyceraldehyde, J. Brazil. Chem. Soc., 16, 467-476, 2005.

Gelencser, A. and Varga, Z.: Evaluation of the atmospheric significance of multiphase reactions in atmospheric secondary organic aerosol formation, Atmos. Chem. Phys., 5, 2823-2831, doi:10.5194/acp-5-2823-2005, 2005.

Glushonok, G. K., Petryaev, E. P., Turetskaya, E. A., and Shadyro, O. I.: Equilibrium between the molecular forms of glycolaldehyde and of DL-glyceraldehyde in aqueous solutions, Zh. Fiz. Khim., 60, 2960-2970, 1986.
Glushonok, G. K., Glushonok, T. G., Maslovskaya, L. A., and Shadyro, O. I.: A $1 \mathrm{~h}$ and $13 \mathrm{c} \mathrm{nmr}$ and uv study of the state of hydroxyacetone in aqueous solutions, Russ. J. Gen. Chem., 73 1027-1031, doi:10.1023/b:rugc.0000007604.91106.60, 2003.

Gubina, T. I., Pankratov, A. N., Labunskaya, V. I., and Rogacheva, S. M.: Self-oscillating reaction in the furan series, Chem. Heterocycl. Compd., 40, 1396-1401, doi:10.1007/s10593-005-0051-5, 2004.

Guthrie, J. P.: Hydration of thioesters. Evaluation of the freeenergy changes for the addition of water to some thioesters, rateequilibrium correlations over very wide ranges in equilibrium constants, and a new mechanistic criterion, J. Am. Chem. Soc., 100, 5892-5904, doi:10.1021/ja00486a048, 1978.

Guzmán, M. I., Colussi, A. J., and Hoffmann, M. R.: Photoinduced oligomerization of aqueous pyruvic acid, J. Phys. Chem. A, 110, 3619-3626, doi:10.1021/jp056097z, 2006.

Guzmán, M. I., Hoffmann, M. R., and Colussi, A. J.: Photolysis of pyruvic acid in ice: Possible relevance to co and $\mathrm{CO} 2$ ice core record anomalies, J. Geophys. Res., 112, D10123, doi:10.1029/2006jd007886, 2007.

Hammond, G. S., Borduin, W. G., and Guter, G. A.: Chelates of beta-diketones. I. Enolization, ionization and spectra, J. Am. Chem. Soc., 81, 4682-4686, doi:10.1021/ja01526a058, 1959.

Haynes, W. M., CRC handbook of chemistry and physics, 93rd Edn., CRC Press, Boca Raton, FL, 6-1, 2012.

Hilal, S. H., Bornander, L. L., and Carreira, L. A.: Hydration equilibrium constants of aldehydes, ketones and quinazolines, QSAR Com. Sci., 24, 631-638, doi:10.1002/qsar.200430913, 2005.

Hine, J. and Mookerjee, P. K.: Structural effects on rates and equilibriums. Xix. Intrinsic hydrophilic character of organic compounds. Correlations in terms of structural contributions, J. Org. Chem., 40, 292-298, doi:10.1021/jo00891a006, 1975.

Hobbs, P. V.: Aerosol-cloud-climate interactions, Academic Press, San Diego, CA, 98-105, 1993.

Hoover, W. G.: Canonical dynamics: Equilibrium phase-space distributions, Phys. Rev. A: At. Mol. Opt. Phys., 31, 1695-1697, 1985.

Horowitz, A., Meller, R., and Moortgat, G. K.: The uv-vis absorption cross sections of the alpha-dicarbonyl compounds: Pyruvic acid, biacetyl and glyoxal, J. Photochem. Photobiol., A, 146, 1927, doi:10.1016/S1010-6030(01)00601-3, 2001.

Hummel, J. R. and Reck, R. A.: A global surface albedo model, J. Appl. Meteorol., 18, 239-253, 1979.

Ip, H. S. S., Huang, X. H. H., and Yu, J. Z.: Effective Henry's law constants of glyoxal, glyoxylic acid, and glycolic acid, Geophys. Res. Lett., 36, L01802, doi:10.1029/2008g1036212, 2009.

IUPAC, Data, C. O. E., Serjeant, E. P., and Dempsey, B.: Ionisation constants of organic acids in aqueous solution, Pergamon Press, 1979.

Jaoui, M., Corse, E., Kleindienst, T. E., Offenberg, J. H., Lewandowski, M., and Edney, E. O.: Analysis of secondary organic aerosol compounds from the photooxidation of d-limonene in the presence of $\mathrm{NO}_{\mathrm{x}}$ and their detection in ambient $\mathrm{PM}_{2.5}$, Environ. Sci. Tech., 40, 3819-3828, doi:10.1021/es052566z, 2006.

Jürgens, M., Jacob, F., Ekici, P., Friess, A., and Parlar, H.: Determination of direct photolysis rate constants and $\mathrm{OH}$ radical reactivity of representative odour compounds in brewery broth using a continuous flow-stirred photoreactor, Atmos. Environ., 41, 4571-4584, doi:10.1016/j.atmosenv.2007.03.053, 2007. 
Karickoff, S. W., Carreira, L. A., and Hilal, S. H.: SPARC performs automated reasoning in chemistry, v4.6, 2011.

Klamt, A. and Schurmann, G.: Cosmo: A new approach to dielectric screening in solvents with explicit expressions for the screening energy and its gradient, J. Chem. Soc., Perkin Trans., 2, 799-805, 1993.

Kwok, E. S. C. and Atkinson, R.: Estimation of hydroxyl radical reaction rate constants for gas-phase organic compounds using a structure-reactivity relationship: An update, Atmos. Environ., 29, 1685-1695, 1995.

Larsen, M. C. and Vaida, V.: Near infrared photochemistry of pyruvic acid in aqueous solution, J. Phys. Chem. A, 116, 5840-5846, doi:10.1021/jp2087972, 2012.

Leermakers, P. A. and Vesley, G. F.: The photochemistry of alphaketo acids and alpha-keto esters. I. Photolysis of pyruvic acid and benzoylformic acid, J. Am. Chem. Soc., 85, 3776-3779, doi:10.1021/ja00906a013, 1963.

Li, S.-M., Macdonald, A. M., Leithead, A., Leaitch, W. R., Gong, W., Anlauf, K. G., Toom-Sauntry, D., Hayden, K., Bottenheim, J., and Wang, D.: Investigation of carbonyls in cloudwater during ICARTT, J. Geophys. Res.-Atmos., 113, D17206, doi:10.1029/2007JD009364, 2008.

Lim, Y. B., Tan, Y., Perri, M. J., Seitzinger, S. P., and Turpin, B. J.: Aqueous chemistry and its role in secondary organic aerosol (SOA) formation, Atmos. Chem. Phys., 10, 1052110539, doi:10.5194/acp-10-10521-2010, 2010.

Mackinney, G. and Temmer, O.: The deterioration of dried fruit. Iv. Spectrophotometric and polarographic studies, J. Am. Chem. Soc., 70, 3586-3590, doi:10.1021/ja01191a013, 1948.

Malik, M. and Joens, J. A.: Temperature dependent near-UV molar absorptivities of glyoxal and gluteraldehyde in aqueous solution, Spectrochim. Acta, Part A, 56, 2653-2658, 2000.

Martinez, A. M., Cushmac, G. E., and Rocek, J.: Chromic acid oxidation of cyclopropanols, J. Am. Chem. Soc., 97, 6502-6510, doi:10.1021/ja00855a036, 1975.

Mayer, B. and Madronich, S.: Actinic flux and photolysis in water droplets: Mie calculations and geometrical optics limit, Atmos. Chem. Phys., 4, 2241-2250, doi:10.5194/acp-4-2241-2004, 2004.

Meylan, W. M. and Howard, P. H.: Bond contribution method for estimating Henry's law constants, Environ. Toxicol. Chem., 10, 1283-1293, doi:10.1002/etc.5620101007, 1991.

Monod, A. and Doussin, J. F.: Structure-activity relationship for the estimation of $\mathrm{OH}$-oxidation rate constants of aliphatic organic compounds in the aqueous phase: Alkanes, alcohols, organic acids and bases, Atmos. Environ., 42, 7611-7622, 2008.

Monod, A., Poulain, L., Grubert, S., Voisin, D., and Wortham, H.: Kinetics of $\mathrm{OH}$-initiated oxidation of oxygenated organic compounds in the aqueous phase: New rate constants, structure activity relationships and atmospheric implications, Atmos. Environ., 39, 7667-7688, 2005.

Nissenson, P., Knox, C. J. H., Finlayson-Pitts, B. J., Phillips, L. F., and Dabdub, D.: Enhanced photolysis in aerosols: Evidence for important surface effects, Phys. Chem. Chem. Phys., 8, 47004710, doi:10.1039/B609219E, 2006.

Nissenson, P., Dabdub, D., Das, R., Maurino, V., Minero, C., and Vione, D.: Evidence of the water-cage effect on the photolysis of $\mathrm{NO}_{3}^{-}$and $\mathrm{FeOH}_{2}^{+}$. Implications of this effect and of $\mathrm{H}_{2} \mathrm{O}_{2}$ surface accumulation on photochemistry at the air-water inter- face of atmospheric droplets, Atmos. Environ., 44, 4859-4866, doi:10.1016/j.atmosenv.2010.08.035, 2010.

Nosé, S.: A molecular dynamics method for simulations in the canonical ensemble, Mol. Phys., 52, 255-268, doi:10.1080/00268978400101201, 1984.

Pavia, D. L.: Introduction to spectroscopy, Brooks/Cole, Belmont, CA, 390-411, 2009.

Perdew, J. P., Ernzerhof, M., and Burke, K.: Rationale for mixing exact exchange with density functional approximations, J. Chem. Phys., 105, 9982-9985, 1996a.

Perdew, J. P., Burke, K., and Ernzerhof, M.: Generalized gradient approximation made simple, Phys. Rev. Lett., 77, 3865-3868, $1996 b$.

Pocker, Y., Meany, J. E., Nist, B. J., and Zadorojny, C.: Reversible hydration of pyruvic acid. I. Equilibrium studies, J. Phys. Chem., 73, 2879-2882, doi:10.1021/j100843a015, 1969.

Raventos-Duran, T., Camredon, M., Valorso, R., Mouchel-Vallon, C., and Aumont, B.: Structure-activity relationships to estimate the effective Henry's law constants of organics of atmospheric interest, Atmos. Chem. Phys., 10, 7643-7654, doi:10.5194/acp10-7643-2010, 2010.

Renard, P., Siekmann, F., Gandolfo, A., Socorro, J., Salque, G., Ravier, S., Quivet, E., Clément, J.-L., Traikia, M., Delort, A.M., Voisin, D., Vuitton, V., Thissen, R., and Monod, A.: Radical mechanisms of methyl vinyl ketone oligomerization through aqueous phase $\mathrm{OH}$-oxidation: on the paradoxical role of dissolved molecular oxygen, Atmos. Chem. Phys., 13, 6473-6491, doi:10.5194/acp-13-6473-2013, 2013.

Renzetti, N. A. and Doyle, D. J.: The chemical nature of the particulate in irradiated automobile exhaust, J. Air Pollut. Control Assoc., 8, 293-296, 1959.

Rice, F. O.: The effect of solvent on the ultra violet absorption spectrum of a pure substance, J. Am. Chem. Soc., 42, 727-735, doi:10.1021/ja01449a009, 1920.

Rogers, J. D.: Rate constant measurements for the reaction of the hydroxyl radical with cyclohexene, cyclopentene, and glutaraldehyde, Environ. Sci. Technol., 23, 177-181, 1989.

Röhrig, U. F., Frank, I., Hutter, J., Laio, A., VandeVondele, J., and Rothlisberger, U.: QM/MM car-parrinello molecular dynamics study of the solvent effects on the ground state and on the first excited singlet state of acetone in water, Chem. Phys. Chem., 4, 1177-1182, doi:10.1002/cphc.200300650, 2003.

Sander, R.: Compilation of Henry's law constants for inorganic and organic species of potential importance in environmental chemistry (version 3), http://www.henrys-law.org, (last access: 1 June 2013), 1999.

Sander, S. P., Abbatt, J., Barker, J. R., Burkholder, J. B., Friedl, R. R., Golden, D. M., Huie, R. E., Kolb, C. E., Kurylo, M. J., Moortgat, G. K., Orkin, V. L., and Wine, P. H.: Chemical kinetics and photochemical data for use in atmospheric studies: Evaluation number 17. JPL Publication 10-6, Jet Propulsion Laboratory, Pasadena, http://jpldataeval.jpl.nasa.gov 5 June 2013, 2011.

Saxena, P. and Hildemann, L. M.: Water-soluble organics in atmospheric particles: A critical review of the literature and application of thermodynamics to identify candidate compounds, J. Atmos. Chem., 24, 57-109, 1996.

Schaefer, T., Schindelka, J., Hoffmann, D., and Herrmann, H.: Laboratory kinetic and mechanistic studies on the $\mathrm{OH}$-initiated ox- 
idation of acetone in aqueous solution, J. Phys. Chem. A, 116, 6317-6326, doi:10.1021/jp2120753, 2012.

Schafer, A., Horn, H., and Ahlrichs, R.: Fully optimized contracted gaussian basis sets for atoms $\mathrm{Li}$ to $\mathrm{Kr}$, J. Chem. Phys., 97, 25712577, 1992.

Schutze, M. and Herrmann, H.: Uptake of acetone, 2-butanone, 2,3butanedione and 2-oxopropanal on a water surface, Phys. Chem. Chem. Phys., 6, 965-971, 2004.

Seinfeld, J. and Pandis, S.: Atmospheric chemistry and physics, John Wiley and Sons, Inc., New York, 1998.

Sham, Y. Y. and Joens, J. A.: Temperature dependent near uv molar absorptivities of several small aldehydes in aqueous solution, Spectrochim. Acta A, 51, 247-251, 1995.

Staffelbach, T. A., Orlando, J. J., Tyndall, G. S., and Calvert, J. G.: The uv-visible absorption spectrum and photolysis quantum yields of methylglyoxal, J. Geophys. Res. Atmos., 100, 14189 14198, doi:10.1029/95JD00541, 1995.

Staudinger, J. and Roberts, P. V.: A critical review of Henry's law constants for environmental applications, Crit. Rev. Environ. Sci. Technol., 26, 205-297, doi:10.1080/10643389609388492, 1996.

Steenken, S., Jaenicke-Zauner, W., and Schulte-Frohlinde, D.: Photofragmentation of hydroxyacetone, 1.3-dihydroxyacetone, and 1.3-dicarboxyacetone in aqueous solution. An EPR study, Photochem. Photobiol., 21, 21-26, doi:10.1111/j.17511097.1975.tb06624.x, 1975.

Sulpizi, M., Carloni, P., Hutter, J., and Rothlisberger, U.: A hybrid TDDFT/MM investigation of the optical properties of aminocoumarins in water and acetonitrile solution, Phys. Chem. Chem. Phys., 5, 4798-4805, doi:10.1039/B305846H, 2003.

Tan, Y., Lim, Y. B., Altieri, K. E., Seitzinger, S. P., and Turpin, B. J.: Mechanisms leading to oligomers and SOA through aqueous photooxidation: Insights from $\mathrm{OH}$ radical oxidation of acetic acid and methylglyoxal, Atmos. Chem. Phys., 12, 801-813, doi:10.5194/acp-12-801-2012, 2012.

Tapavicza, E., Meyer, A. M., and Furche, F.: Unravelling the details of vitamin d photosynthesis by non-adiabatic molecular dynamics simulations, Phys. Chem. Chem. Phys., 13, 20986-20998, doi:10.1039/C1CP21292C, 2011.

Tapavicza, E., Vincent, J. C., Bellchambers, G. D., and Furche, F.: $\mathrm{Ab}$ initio non-adiabatic molecular dynamics Phys. Chem. Chem. Phys., doi:10.1039/C3CP51514A, 2013.
Treutler, O. and Ahlrichs, R.: Efficient molecular numerical integration schemes, J. Chem. Phys., 102, 346-354, 1995.

Turýan, Y. I.: Kinetics and equilibrium of the dehydration-hydration and recombination dissociation reactions of glyoxylic acid investigated by electrochemical methods, Croat. Chem. Acta,, 71, 727-743, 1998.

van Pinxteren, D., Plewka, A., Hofmann, D., Müller, K., Kramberger, H., Svrcina, B., Bächmann, K., Jaeschke, W., Mertes, S., Collett Jr, J. L., and Herrmann, H.: Schmücke hill cap cloud and valley stations aerosol characterisation during FEBUKO (ii): Organic compounds, Atmos. Environ., 39, 4305-4320, doi:10.1016/j.atmosenv.2005.02.014, 2005.

Vione, D., Maurino, V., Minero, C., Pelizzetti, E., Harrison, M. A. J., Olariu, R.-I., and Arsene, C.: Photochemical reactions in the tropospheric aqueous phase and on particulate matter, Chem. Soc. Rev., 35, 441-453, doi:10.1039/b510796m, 2006.

Wallington, T. J., and Kurylo, M. J.: Flash photolysis resonance fluorescence investigation of the gas-phase reactions of $\mathrm{OH}$ radicals with a series of aliphatic ketones over the temperature range 240 440 k, J. Phys. Chem., 91, 1987.

Weigend, F. and Häser, M.: RI-MP2: First derivatives and global consistency, Theor. Chem. Acc., 97, 331-340, doi:10.1007/s002140050269, 1997.

Winkelman, J. G. M., Voorwinde, O. K., Ottens, M., Beenackers, A. A. C. M., and Janssen, L. P. B. M.: Kinetics and chemical equilibrium of the hydration of formaldehyde, Chem. Eng. Sci., 57, 4067-4076, 2002.

Xu, H., Wentworth, P. J., Howell, N. W., and Joens, J. A.: Temperature dependent near-uv molar absorptivities of aliphatic aldehydes and ketones in aqueous solution, Spectrochim. Acta A, 49, 1171-1178, 1993.

Zhou, S. M., Barnes, I., Zhu, T., Bejan, I., Albu, M., and Benter, T.: Atmospheric chemistry of acetylacetone, Environ. Sci. Technol., 42, 7905-7910, 2008

Zhou, X. and Mopper, K.: Apparent partition coefficients of 15 carbonyl compounds between air and seawater and between air and freshwater; implications for air-sea exchange, Environ. Sci Tech., 24, 1864-1869, doi:10.1021/es00082a013, 1990. 